\title{
La Economía del Estado Estacionario: ¿El único camino hacia un futuro sostenible?
}

Fecha de recepción: 17 de octubre de 2008

Fecha de aprobación: 12 de diciembre de 2008

* Profesor Universidad Autónoma de Barcelona, España. christian.kerschner@gmail.com 
Los economistas ecológicos (p.ej.: Herman Daly) dicen que el desarrollo sostenible solo puede alcanzarse mediante un drástico cambio en nuestro sistema económico basado en el crecimiento. El crecimiento económico continuo siendo éste el objetivo de cualquier gobierno, es inherentemente incompatible con el desarrollo sostenible, a menos que el desarrollo sostenible sea definido de forma débil; es decir aceptando sustituibilidad entre capital producido por el hombre y capital natural. Esto ya se lleva actualmente a cabo por la teoría económica neoclásica, las raíces de la cual se encuentran en el concepto del valor, análogo al principio de conservación de la mecánica clásica. Algunos autores esgrimen que es este concepto del valor, combinado con la panacea del progreso tecnológico, lo que permite a la teoría económica neoclásica creer en un crecimiento económico ilimitado.

No solo el crecimiento económico continuo es físicamente imposible (p.ej.: la hipótesis de la desmaterialización es un mito) dadas las interpretaciones de Georgescu Roegen al respecto de las leyes de la termodinámica, sino también indeseable. Varios estudios (p.ej.: cálculos del Índice de Bienestar Económico Sostenible) sugieren que el actual bienestar de la sociedad humana no esta aumentando, sino de hecho está disminuyendo a medida que aumenta todavía más el crecimiento económico.

La alternativa al crecimiento y al decrecimiento es el estado estacionario. La mayor parte de los economistas clásicos reconocen la existencia de un estado estacionario, incluyendo Adam Smith, Thomas Malthus, Karl Marx y John Stuart Mill. Todos ellos tenían sus ideas al respecto de este estado; unos lo igualaban con el desastre, otros lo glorificaban. Sin embargo, la mayoría tenían una visión positivista al respecto.

Herman Daly apoya la visión de Mill de un estado estacionario positivo p.ej.: inevitable, pero también normativo. Él cree que la humanidad debería aproximarse a una economía en estado estacionario (EEE) antes de verse forzada a ello. Daly ofrece un marco político teórico simple que puede usarse para tal meta. Se necesitan tres instituciones para estabilizar el sistema en un nivel constante. La primera estaría al cargo de estabilizar la población mundial, cosa que es inevitable. La segunda institución introduciría cuotas de recolección, que serían subastadas por el gobierno, con el objetivo de reducir la utilización de materiales y energía (throughput). Finalmente una institución distribuidora debería asegurar la justicia social mediante la introducción de límites máximos y mínimos a las rentas.

Obviamente este es un concepto muy controvertido y ha sido mayormente ignorado por los académicos o descartado por utópico. Robert Ayres argumenta que dada suficiente energía, la cual puede ser generada encontrando nuevas maneras de capturar los abundantes rayos solares, casi cualquier cosa puede ser reciclada, permitiendo incluso más crecimiento económico. Hay diversos defectos en las ideas de Daly y hay cuestiones que deberían ser discutidas (p. ej. Importaciones, expropiación de la riqueza, incentivos al emprenderismo). Un aspecto importante es si el funcionamiento del capitalismo puede ser mantenido en un estado estacionario. Mill, Marx, Schumpeter y Keynes, implícitamente asumieron que una economía en estado estacionario 


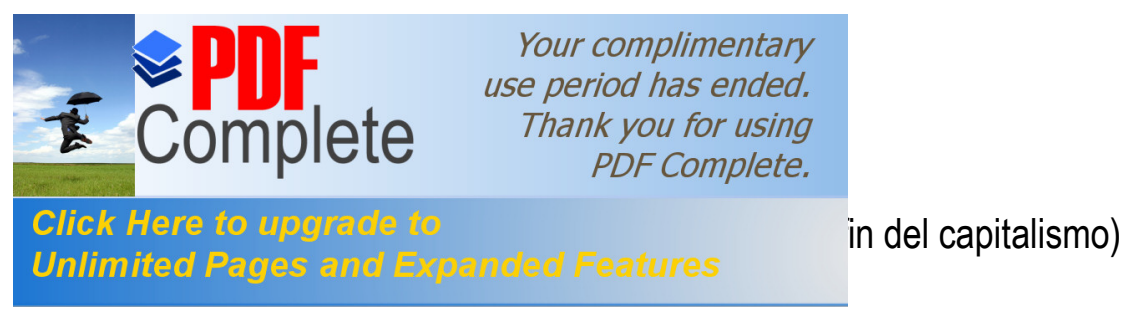

A pesar de esas carencias en el concepto de EEE de Daly, estas no justifican un rechazo a su enfoque y al estado estacionario como tal, si no que debería estimular el desarrollo de otros conceptos o sugerencias para su mejora. El discurso de la sostenibilidad no puede y no debe ignorar el concepto de estado estacionario.

Palabras Clave: Crecimiento Económico, desarrollo sostenible, estado estacionario

\section{ABSTRACT}

Ecological Economists (e.g.: Herman Daly) claim that sustainable development can only be achieved by drastically changing our growth based economic system. Continuous economic growth, which is the goal of every government, is inherently incompatible with sustainable development, unless sustainable development is defined in a weak sense; that is as accepting substitutability between human made and natural capital. This is currently done by neoclassical economic theory, the roots of which are based on a value concept, analogous with the conservation principle of classical mechanics. Some authors argue that it is this value concept combined with the panacea of technological progress, which allows neoclassical economic theory to believe in unlimited economic growth.

Not only is continuous economic growth physically impossible (i.e.: the dematerialization hypothesis is a myth), given Georgescu-Roegen's interpretations of the laws of thermodynamics, but also undesirable. Various studies (e.g.: calculations of the Index of Sustainable Economic Welfare) suggest that the actual wellbeing of the human society is not increasing, but in fact decreasing with further growth of the economy.

The alternative to growth or decline is the steady state. Most classical economists acknowledged the existence of a steady state, including Adam Smith, Thomas Malthus, Karl Marx and John Stuart Mill. They all had their own ideas about such a state; some equated it with disaster, others glorified it. However, most of them had a positivistic concept of such a state.

Herman Daly supports Mill's view of a positive i.e.: inevitable, but also normative steady state. He believes that humanity would be well advised to bring about a steady state economy (SSE) before it is forced upon it. Daly offers a theoretically simple political framework, which could be used for such a goal. Three institutions are to be employed to stabilise the system at a constant level. The first one would be in charge of stabilising the human population, which is inevitable. The second institution introduces depletion quotas, which are auctioned by the government, in order to reduce material and energy throughput. Finally a distributionist institution ought to secure social justice by introducing minimum and also maximum income limits.

Obviously this is a very controversial concept and has been mostly ignored by fellow scientists or rejected as utopia. Robert Ayres argues that given enough energy, which could be generated by finding new ways to capture the abundant solar rays, almost anything could be recycled, allowing for even more economic growth. There are many flaws within Daly's ideas and there are issues, which 


\section{I IE Your complimentary use period has ended.

iation of the rich, entrepreneurial incentives). One important capitalist system could be maintained in a steady state. Mill, Marx, Schumpeter and Keynes, all implicitly assumed that a steady-state economy would be equal to socialism (or at least the end of capitalism).

Nevertheless these flaws in Daly's SSE concept do not justify a rejection of his approach and of the steady state as such, but should give rise to the development of other concepts or suggestions for its improvement. The sustainability discourse cannot and should not ignore the concept of a steady state.

Key Words: economic growth, sustainable development, steady state. 


\section{INTRODUCCION}

Por lo menos des del informe de la Comisión Brundtland (WCED 1987), sostenibilidad y desarrollo sostenible son palabras recurrentes entre políticos e instituciones internacionales. El verdadero significado de estas palabras y sus implicaciones, sin embargo, resta todavía hoy ambiguo. De hecho se supone que la única razón por la cual existe tan amplio apoyo al concepto de sostenibilidad es que fue definido vagamente por los autores (Costanza, Norgaard et al. 1997). Tampoco la Comisión Brundtland distinguió entre sostenibilidad fuerte o débil, ni apuntaron al grave conflicto entre sostenibilidad y crecimiento. Dado que la Tierra es finita y no-creciente, cualquier subsistema físico eventualmente debe convertirse en no-creciente. Se desprende pues que el crecimiento económico y el desarrollo sostenible son incompatibles. El primero se refiere a la expansión cuantitativa en la escala de la dimensión física de un sistema económico, mientras que el último debe referirse al cambio cualitativo en un sistema económico físico no-creciente en dinámico equilibrio con el entorno (Costanza, Norgaard et al. 1997). El debate moderno sobre el crecimiento ${ }^{1}$ es, no obstante, anterior al informe Brundtland. El influyente informe del Club de Roma, Los límites del crecimiento, por Meadows et al. (1972), predijo una inminente agotamiento de los recursos naturales usando un modelo mundial integrado. Incluso antes de eso algunos autores señalaron los límites impuestos por la segunda ley de la termodinámica para los sistemas económicos (Boulding 1966; Georgescu-Roegen 1971).

El objetivo de este articulo es primero analizar los orígenes de lo que nos referimos como "paradigma del crecimiento", Luego se discutirán las posibilidades físicas y la deseabilidad socioética del crecimiento económico continuo. Las dos partes finales del articulo presentan la economía del estado estacionario (o economía estacionaria) como la única alternativa sostenible a la economía del crecimiento. Después de revisar la historia teórica de este concepto alternativo, se presentan y se analizan críticamente las visionarias instituciones propuestas por Herman Daly (1992a) para acercarse al estado estacionario.

\section{EL PARADIGMA DEL CRECIMIENTO Y SU BASE TEÓRICA}

La economía comenzó como una rama de la filosofía moral, en la cual el contenido ético fue al menos tan importante como el analítico. Esto fue así hasta los escritos de Alfred Marshall (Brandis, 1989). En los Principios de Economía (1890), Marshall estableció la teoría económica neoclásica como la principal teoría económica. A partir de entonces, según Daly (1992a, p. 3), "(...) la estructura de la teoría económica se hizo más alta y más pesada con el análisis. Capa sobre capa abstractos modelos matemáticos se elevaron más y más por encima de la base de los hechos."

Stanley Jevons (1835 -1882) propuso cambiar el nombre de lo que entonces se llamaba Economía

1 El "debate del crecimiento" en si mismo probablemente se remonta a los escritos de Thomas Malthus en el siglo XVIII. 
ras fue parejo con el más importante cambio de paradigma Ello dio lugar a una "destrucción del sistema clásico" (Schumpeter 1970 [1908]), con consecuencias de largo alcance. Motivados por los éxitos de las ciencias naturales, en particular, la física y la mecánica clásica, se esforzaron en establecer la economía como una disciplina más científica. Éste fue un resultado directo de un influyente movimiento filosófico de la década de 1920 y principios de 1930, llamado positivismo lógico. Se originó a partir del Círculo de Viena, un grupo difuso de filósofos, dirigido por Moritz Schlick (Okasha 2002).

La economía adoptó poco a poco una filosofía mecanicista en el período comprendido entre 1870 y 1939 (Wiener 1966), culminando con los Principios de Marshall (1890). El campo de la teoría del valor, que se basa en el ámbito de la energía de la mecánica clásica se convirtió en el núcleo de la teoría económica neoclásica. El valor es sinónimo de utilidad y por lo tanto, ya no reside en los productos, sino en la mente de las personas (es decir, las preferencias de la gente) (Söllner 1997). E resultado del comportamiento humano objetivo de maximizar la utilidad también se origina en la analogía entre la energía y la utilidad. A partir de ese momento los conceptos normativos se convirtieron en exógenos a la teoría económica, las cuestiones éticas son ahora una cuestión de gusto personal y la economía surgió como simple "mecánica de la utilidad y el interés propio" (Jevons 1924). Los economistas plenamente aceptaron "el modo de pensamiento mecanicista, reduccionista y positivista" (Daly 1992a, p. 20) en ese momento. Las consecuencias son de largo alcance, en particular con respecto a la posición del ecosistema en relación con la economía.

Incluso hoy en día la economía es a menudo retratada como un sistema cerrado, aislado, en los libros de texto, similar a un reloj (Georgescu-Roegen 1971), o el modelo de flujo circular modelo representado en la Figura 1 (Daly 1996; Martínez-Alier y Roca 2000). Por lo tanto, no hay entradas y salidas de y hacia el medio ambiente. El suministro de los los recursos y la capacidad para absorber los residuos, por lo tanto, no se perciben como factores limitantes para el desarrollo económico. Sin embargo a finales de los años 60 y principios de los 70, los problemas ambientales se hicieron más y más evidentes y este modelo económico fue impugnado, probablemente las críticas más conocidas fueron el concepto de "nave espacial tierra" de Boulding (1966) los límites al crecimiento de Meadows et al. (1972) La respuesta a estos acontecimientos fue la creación de la subdisciplina de la economía del medio ambiente, pero se basa en los mismos fundamentos, es decir, la analogía energética, como la economía neoclásica y, por tanto, está afectada por las mismas deficiencias (Söllner 1997).

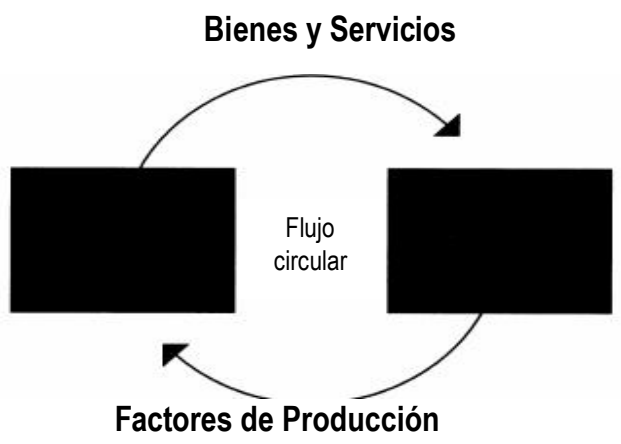

Figura 1. La economía como un sistema aislado (extraído de Daly, 1996 p. 47) 
E Complete $\begin{array}{r}\text { Your complimentary } \\ \text { use period has ended. } \\ \text { Thank you for using } \\ \text { PDF Complete. }\end{array}$

Click Here to upgrade to

Unlimited Pages and $=x$

que, en principio, pueden ser sustituibles sin restricciones.

Aunque esto podría ser cierto para algunos productos y materias primas, es ridículo suponer que el cobre, por ejemplo, podría sustituir el arroz en la dieta humana. Sin embargo los economistas ortodoxos (por ejemplo: Barnett y Morse 1963) rechazan el concepto de escasez absoluta propugnado por Daly (1992a), para ellos los recursos solo son escasos con relación a otro recurso, u otra (menor) calidad del mismo recurso. La escasez relativa puede ser superada por la sustitución, en la que los recursos relativamente escasos son eventualmente sustituidos por los relativamente abundantes. Los recursos son, por lo tanto, ilimitados, en total y sólo falta homogeneidad en la calidad. Los avances de la ciencia y la tecnología permiten superar este obstáculo al hacerlos más homogéneos

Según Daly (1992) los medios últimos en forma de materia/energía de baja entropía son escasos en términos absolutos. Es decir, que existen límites absolutos a partir de la cual la disponibilidad es nula. La eficiencia distributiva de los mercados, sobre la base del mecanismo de los precios, que es el foco de la teoría económica neoclásica, sólo puede hacer frente a la escasez relativa y no a la absoluta. Dado que no hay sustituto para la materia/energía de baja entropía, elevar los precios relativos de todos estos recursos simplemente aumentaría el nivel de precios absolutos y provocaría inflación. Desde Meadows et al. (1972) se puso de manifiesto que en términos de sostenibilidad, la escasez absoluta de los sumideros va a ser incluso más problemática para las generaciones futuras que la de los recursos naturales. Es posible que sea mucho más fácil para las futuras generaciones encontrar un sustituto para el petróleo que hacer frente al cambio climático, por ejemplo. La economía del medio ambiente se propone contrarrestar las presiones sobre el medio ambiente, a las cuales consideran externalidades negativas, a través de la internalización vía impuestos pigouvianos. Esta estrategia, una vez mas ignora el hecho que la mayor parte de los servicios proporcionados por la naturaleza son escasos en un sentido absoluto.

La llamada interpretación débil de la sostenibilidad se basa también en la sustituibilidad de factores. El capital hecho por el hombre se supone que es un sustituto perfecto para el capital natural. Por lo tanto, la pérdida o degradación de las existencias de capital natural (recursos y los sumideros) a las generaciones futuras está siendo compensada por el capital que es creado por el hombre (estructuras construidas, tecnologías desarrolladas, conocimientos acumulados, etc.) El hecho de que prácticamente todos los objetos producidos sean "perecederos" (Ricardo 1817), es decir, que se deprecian, es completamente ignorado. La mayoría de ellos probablemente tendrán que ser sustituidos en su totalidad dentro de los 100 años (Viktor 1991) (lo mismo podría argumentarse de la tecnología y el conocimiento).

Capital natural y capital hecho por el hombre son, en efecto, complementos y no sustitutivos. Esto a menudo se ha ilustrado con el ejemplo de la industria pesquera. Históricamente, en un "economíamundo vacía" (véase más adelante), el factor escaso eran los barcos de pesca (capital hecho por el hombre). Este papel ha cambiado a lo largo de las últimas décadas. Ahora que vivimos en una "economía-mundo llena" el factor escaso es el pescado (capital natural). Nuevos barcos de pesca equipados con alta tecnología no aumentan la cantidad de peces capturados, de hecho ocurre lo contrario. Mientras tanto la sobre-pesca ha dado lugar a una disminución del stock mundial de peces que ha visto reducida drásticamente su capacidad reproductiva. Por lo tanto, la industria pesquera 
En segundo lugar, el concepto mecánico del valor tiene un fuerte impacto en el tratamiento del tiempo en la teoría económica neoclásica. A veces incluso se niega su propia existencia. En los casos en que el tiempo se tiene en cuenta, es tratado de forma mecánica. No existe la incertidumbre, todo es conocido, ya sea con absoluta seguridad o en forma de distribución de probabilidad (Georgescu-Roegen 1971 ch. 5-8; Edmonds y Reilly 1985; Perrings 1987). Además, la interacción entre la economía y el medio ambiente, se supone que se produce en unidades infinitesimales, cualitativamente idénticas y reversibles sin la consideración de posibles umbrales 0 puntos de no retorno (Söllner 1997). La reversibilidad, por lo tanto, deja vía libre a la humanidad para talar los bosques, porque podrían ser replantados; contaminar los suministro de agua dulce, ya que podría ser de-contaminados; explotar especies en peligro de extinción, ya que podrían volver a introducirse a partir de las existencias en los parques zoológicos y jardines botánicos o ser reproducido en los laboratorios de ingeniería genética, etc, En realidad, "por supuesto, todos los procesos económicos reales (y otros) son irreversibles." (Söllner 1997 p. 181, énfasis propio).

Por último el optimismo tecnológico parece actuar como un mecanismo de refuerzo y "tapar lagunas" en la teoría económica neoclásica. Facilita tanto la hipótesis de la sustitución de factores (es decir, el rechazo de la escasez absoluta) como la asunción de la reversibilidad. El progreso tecnológico humano parece ser la panacea para los economistas. Este optimismo no esta en modo alguno justificado (Aage 1984) ya que las leyes de la termodinámica siempre imponen límites. Por supuesto, en el pasado leyes físicas se han demostrado falsas, pero según la mayoría de físicos, entre los cuales Albert Einstein, las leyes de la termodinámica son las que son menos probables de ser derrocadas (Daly 1992).

\subsection{Muchos problemas una solución}

La economía neoclásica no demanda el crecimiento económico como tal, sino que proporciona las condiciones teóricas previas para ello y considera que es una "evidente necesidad" (GeorgescuRoegen 1977). Los economistas ortodoxos están convencidos de que sólo el crecimiento económico puede resolver los "problemas clásicos" de la sociedad, formulados por Smith (la pobreza), Malthus (superpoblación), Marx (la distribución) y Keynes (desempleo involuntario). No sólo eso, también es ofrecido como uno (o el único) modo de solucionar los problemas de contaminación, el reembolso de la deuda, la balanza de pagos, el agotamiento de los los recursos naturales, la delincuencia, etc La mayoría de estas reclamaciones están respaldadas por teorías más o menos plausibles, la mayoría de las cuales apenas apoyadas por estudios empíricos. Sólo la pobreza y la contaminación del medio ambiente, se considerarán más de cerca en este artículo.

En primer lugar el crecimiento económico es como la "marea alta que eleva todos los barcos" (Daly 2001, p. 15). A pesar de que no supone un aumento de todos los ingresos relativos, se supone que debe hacerlo con los ingresos absolutos. Si la torta se hace más grande, entonces todo el mundo puede (podría) obtener un pedazo más grande. Esta es la filosofía dominante en la mayoría de los gobiernos y organizaciones internacionales. En realidad el crecimiento se ha traducido en una ampliación de la brecha entre los ingresos de los más pobres y los más ricos (Daly 2001). El FMl 
sar del crecimiento en Occidente, y en algunos de los países Unlimited Pages and Expandedeo lación del mundo ha retrocedido (Palacio 2001). La metáfora en sí misma parece inapropiada para este argumento, porque es un hecho que la marea alta en una parte del mundo causa la marea baja en otra.

En segundo lugar, se alega que las sociedades que experimentan un crecimiento económico eventualmente comienzan a valorar su naturaleza como un "bien de lujo" y empiezan a proteger y reparar el daño ya hecho (por ejemplo: Banco Mundial 1992). Selden y Song (1994) anunciaron la hipótesis que la relación medio ambiente - riqueza podría ser similar a la presentada por Premio Nobel Simon Kuznets entre la desigualdad de la renta y el desarrollo económico. Seldon y Song (1994) alegaron inicialmente que el crecimiento económico se traduce en mayor contaminación, pero eventualmente se invierte, produciendo una curva en forma de $U$ invertida, la llamada curva ambiental de Kuznets (EKC). Si bien esta hipótesis goza apoyo empírico para algunos contaminantes (Cavlovic, Baker et al. 2000), no es el caso por ejemplo del dióxido de carbono (HoltzEakin y Selden 1995) y otros importantes contaminantes del aire (W. Harbaugh, Levinson et al. 2000).

Por otra parte, la hipótesis EKC se caracteriza por una variedad de fallas conceptuales fundamentales, que han sido descritos en detalle por Tisdell (2001). Muchos de estos defectos se originan a partir de la analogía mecánica discutida anteriormente. Se supone que la contaminación no es acumulativa y sus efectos son reversibles. En realidad se trata de un conocido hecho que algunos contaminantes son acumulativos o podrían ser considerados como tales debido al largo tiempo que necesitan para ser descompuestos por el ecosistema (por ejemplo: emisiones de CO2 0 CFCs). Además no todos los daños al medio ambiente son reversible, como, por ejemplo, la pérdida de la diversidad biológica. Se pueden cruzar umbrales después de los cuales los ecosistemas podrían derrumbarse y/o requerir cientos de años para recuperarse.

Relacionado con la EKC encontramos la "hipótesis de la desmaterialización" o "des-enganche (decoupling, en su voz inglesa)". Se basa en el argumento que las economías devienen más orientadas hacia los servicios y los conocimientos a medida que crecen y, por tanto, utilizan menos recursos naturales. Tal disociación se alcanza en un sentido absoluto 0 en relación con el PIB (desmaterialización débil). Si se adopta su definición débil, entonces, esta última sería suficiente para lograr la sostenibilidad. La contabilidad de flujos de materiales y energía, la cual ha experimentado grandes avances en los últimos años, continúa proporcionando fuerte evidencia empírica contra la desmaterialización (Haberl, Fischer-Kowalski et al. 2004). Aunque hay algunas economías que experimentan una desmaterialización débil , por ejemplo: Austria (Krausmann, Haberl et al. 2004), existen numerosos ejemplos, en particular de los países del sur, donde ni siquiera la desmaterialización débil puede observarse por ejemplo: España (Cañellas, Citalic González et al. en prensa), Grecia (Eurostat 2002) y Chile (Giljum 2004). Además, se alegó que los países industrializados, que logran la desmaterialización débil o fuerte, lo hacen a cambio de trasladar el "peso ambiental" hacia el sur, a los países menos desarrollados. Esta hipótesis es conocida como "desplazamiento de carga ambiental" (Giljum 2004; Cañellas, Citalic González et al. en prensa) 


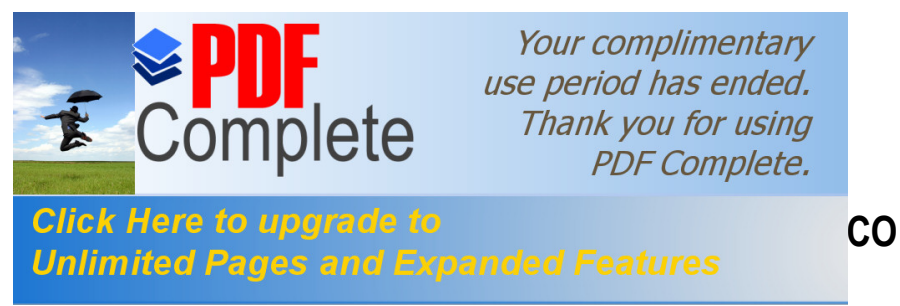

En la teoría microeconómica la escala óptima de una actividad microeconómica (producción de una empresa o consumo de un hogar) se determina en el punto en el cual los costes marginales son iguales al beneficio marginal. Es más, variaciones de la solución de este problema dominan la teoría microeconómica. La ley de los rendimientos decrecientes a escala indica que después del punto óptimo un mayor crecimiento se convierte en no rentable, porque los costes son superiores al beneficio. No se conoce un concepto similar en la teoría macroeconómica. Según Daly (2001), la razón de ello es que la microeconomía sólo considera partes - el crecimiento de cada una de las partes está limitado por los costos de oportunidad, que el resto del sistema tiene que soportar. La Macroeconomía, por otra parte sólo considera la totalidad y el crecimiento de la totalidad no causa costes de oportunidad, porque el 'resto', que tendrían que soportar estos costes, no existe (Daly 2001).

En ausencia de los costes de oportunidad, no existe una escala óptima para la actividad económica y, por tanto, no hay límites para el crecimiento económico. Este crecimiento ha generado los avances de nuestra sociedad moderna, al menos en occidente, en ausencia de costes de oportunidad, más grande sólo puede significar mejor. Este mundo ignora por completo el papel del medio ambiente como proveedor de bienes y servicios vitales. Como ya se ha mencionado anteriormente, la economía es un sistema cerrado. Es cierto que el aumento de la economía del medio ambiente logró reconocer del valor de estos servicios (comparar: Costanza, d'Arge et al. 1997). Sin embargo, el medio ambiente es visto como un subsistema de la economía (Figura 2), que tiene que estar sometido a los dictámenes de los mecanismos del mercado. En otras palabras, las externalidades negativas deben ser internalizadas y un valor económico (en términos de dinero) debe ser atribuido a los servicios de la naturaleza (por ejemplo: vía evaluación contingente, los costes de trasporte o la fijación de precios hedónicos). Detalles y críticas de estos enfoques se examinan en detalle en otros artículos (por ejemplo: Martínez-Alier y Roca 2000) y están más allá del ámbito de aplicación de este documento.

Debido a las posibilidades de sustitución y el progreso tecnológico, el subsector ambiental no impone límites a la extensión de la economía al como la figura 2 ilustra claramente. La economía ecológica ofrece una perspectiva más "Copernicana", dado que la economía humana no es vista como una totalidad, sino como un subsistema del ecosistema. La Figura 3 es fundamental para el paradigma de la economía ecológica y resume esta "visión del mundo": la economía es representada como un subsistema del ecosistema en general, que tiene límites y está cerrado. Sólo en lo que respecta al flujo de energía solar puede ser visto como abierto, sin embargo, el flujo solar es limitado y no creciente. 


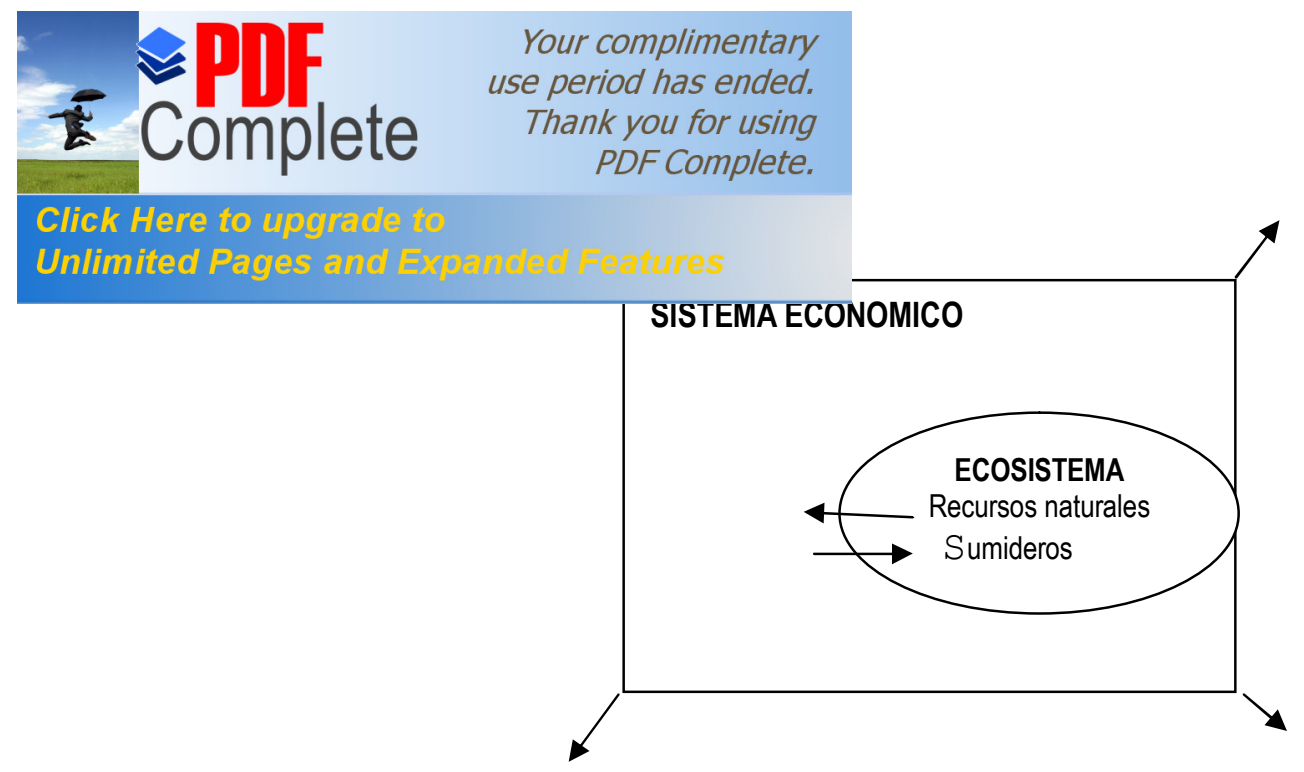

Figura 2: El ecosistema como subsistema de la macroeconomía (extraído de: Daly 2001 p. 8)

La figura 3 muestra dos fuentes del bienestar humano: los servicios de la economía y los servicios del ecosistema. Un crecimiento de la economía va a transformar el capital natural en capital humano, lo que resulta en un mayor flujo de servicios de la economía y uno más pequeña de los ecosistemas. Por otra parte el crecimiento de los servicios de la economía se reduce con un sistema económico cada vez mayor, debido a la ley de la utilidad marginal decreciente. Suponiendo racionales a los seres humanos, las necesidades más urgentes se solventan primero. Dado que la economía reclama cada vez más 'espacio' frente al ecosistema, la sociedad tiene que prescindir cada vez más de los servicios del ecosistema. Suponiendo un comportamiento racional, los servicios menos importantes serán los que se prescinda primero.

Por lo tanto, existen costes de oportunidad en la expansión de la economía, y hay una escala óptima para una

economía, más allá de la cual el crecimiento se vuelve no rentable. La escala óptima podría definirse como una en la cual se maximiza el total de los servicios recibidos, tanto desde la economía como desde el ecosistema (esta cuestión se examina más adelante). Sin embargo, el concepto microeconómico de los costes de oportunidad debe aplicarse con cautela, debido a la interrelación de los servicios de los ecosistemas, es decir, un servicio aparentemente sin importancia podría afectar a otros servicios, debido a una reacción en cadena, que son importantes para la humanidad. A pesar de los considerables avances en la ciencia, la interrelación y la complejidad de los ecosistemas y el clima en la Tierra están todavía lejos de ser plenamente comprendidos. De hecho la complejidad de los sistemas (naturales) es ahora ampliamente reconocida y estudiada (MartínezAlier, Munda et al. 1998). Tratar de determinar una escala óptima simplemente con métodos económicos, por lo tanto, es una tarea de enormes proporciones y puede no ser apropiada.

Inicialmente, cuando la disciplina de la economía (incluida la teoría económica neoclásica) surgió, la pérdida de servicios de los ecosistemas era posiblemente insignificante, dado que las economías siguen siendo pequeñas. Como se muestra en la Figura 3, la sociedad humana vivía en un "mundo vacío" (Costanza, Norgaard et al. 1997): vacío de las personas y sus objetos, pero llena de capital natural. Desde la década de los setenta hay evidencia que la humanidad vive ahora en un "mundo Ileno", p. ej.: la superpoblación (Holdren y Ehrlich 1971), acercamiento a los límites de la posible apropiación humana de la biomasa (Vitousek, Ehrlich et al. 1986); el cambio climático (IPCC 2002); 
A 2000); la degradación de la tierra (Pimentel, Allen et al. ta (Goodland 1991) y la escasez mundial del agua (Shiva 2002).

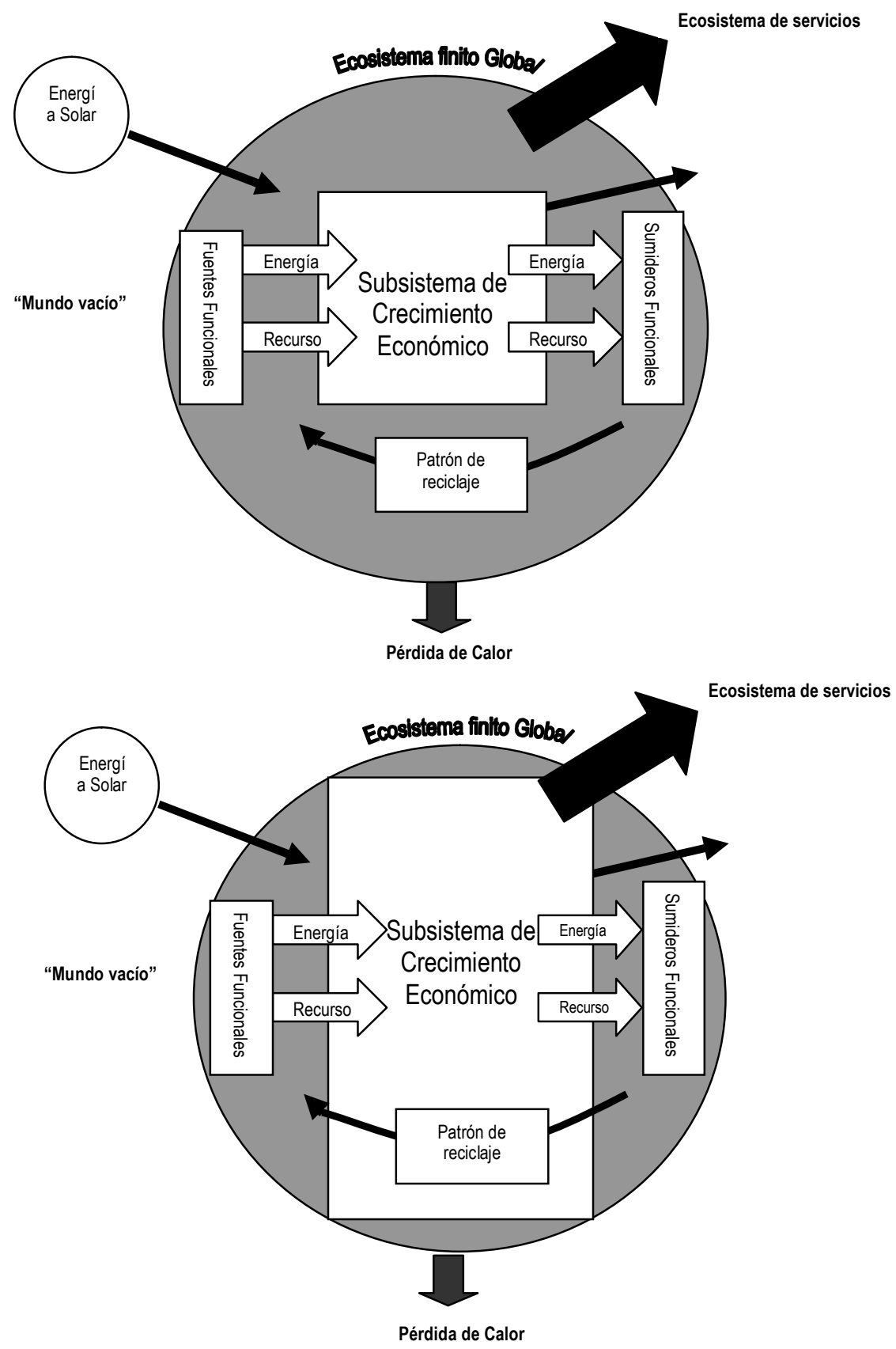

Figura 3: el ecosistema finito global respecto el subsistema económico (extraído de Goodland, Daly et al. 1992; reproducido en: Costanza, Norgaard et al. 1997, p. 6) 


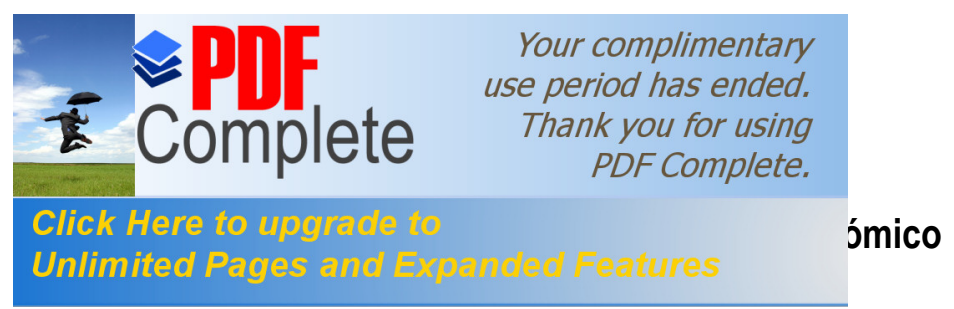

Normalmente cuando uno habla de crecimiento económico, suele referirse al incremento del Producto Nacional Bruto (PNB) o del Producto Interior Bruto (PIB). Como instrumento de contabilidad el PNB es perfectamente legítimo. Sin embargo, su uso como indicador de riqueza o bienestar es altamente problemático. Daly (1992a) argumenta que el PNB suma tres categorías, las cuales son muy distintas y deberían mantenerse separadas: throughput, incrementos del stock de capital y servicios generados por este stock de capital. El throughput se define como el flujo de recolección o contaminación entrópica y es el "coste físico en última instancia" (Daly 1992a, p. 30) de la actividad económica. Por lo tanto, maximizar el PNB implica en cierta medida maximizar los costes! Los servicios prestados por el capital físico y humano son beneficio o renta psíquica. Los incrementos del stock de capital representan la potencialidad de prestar servicios en el futuro, pero sus costes (throughput) han sido ya efectuados. Solamente cuantificando estas magnitudes por separado, sería alguien capaz de determinar si el crecimiento contribuye aún a aumentar el bienestar económico.

Cabe mencionar también que el PNB contiene lo que se ha definido como "necesidades deplorables" (Daly 1992) o "gastos de defensa" (Leipert 1989). Esto incluye gastos de reparación de los daños ambientales (por ejemplo: recogida de residuos), sino también malbaratamiento de tiempo y recursos debidos al estilo de vida moderno (por ejemplo: tiempo perdido debido a los atascos de tráfico, accidentes de coche, etc.) Estos costes aumentan el PNB en lugar de reducirlo. Teniendo en cuenta estos hechos, parece bastante contra intuitivo argumentar que el PNB mide el bienestar económico. De hecho casi nadie explícitamente lo hace. El problema es, sin embargo, que "todo el mundo lo está usando de una manera como si lo fuera." (Stockhammer, Hochreiter et al. 1997, p. 19)

Desde que el PNB empezó a utilizarse como medida de bienestar indirecta, fue recibido con escepticismo. Desde Boulding, en los años 1950 a Daly en la década de 1970. Numerosos han sido los intentos de ampliar/modificar el PNB (p. ej.: 1988; El Serafy 1997) o para desarrollar mejores indicadores de contabilidad nacional, como la Medida de Bienestar Económico (MEW) (Nordhaus y Tobin, 1972); los Aspectos Económicos de Bienestar Social (EAW) (Zoltas 1981), el Índice Sostenible de Riqueza Económica (ISEW), el Indicador de Progreso Genuino (GPI) (Redefining Progress 1995), o más recientemente, el Índice de Beneficio Neto Sostenible (SNBI) (Lawn y Sanders 1999; Lawn 2000). Las pruebas obtenida de aplicaciones empíricas de estos indicadores, en particular, el ISEW, IPS y SNBI, sugieren que en muchos países industriales el crecimiento económico se ha convertido en perjudicial para el bienestar humano (Lawn 2003).

La figura 4 muestra la versión revisada del ISEW de Austria con una creciente brecha entre las dos mediciones (ISEW Y PIB), especialmente desde la década de 1970. Daly y Cobb sin embargo hicieron hincapié en la necesidad de un uso cauteloso de estos indicadores económicos alternativos. Sostienen que cualquier indicador resumen de muchas características reales de bienestar económico. Uno tiene que evitar la falacia de concreción fuera de lugar, que se describe como "la falacia que se produce cuando los pensadores olvidan el grado de abstracción implicado en el razonamiento y sacan conclusiones injustificadas acerca de la realidad concreta" (Daly y Cobb 1989, p. 36). Lo ideal sería que los encargados de formular políticas y los analistas tuvieran varios indicadores disponibles, pero esto también puede plantear problemas en los casos en que cada uno de los indicadores apunte en direcciones opuestas. 
edidas alternativas ha sido mínimo², el recién salido campo de la ecología industrial ofrece nuevas herramientas, que podrían ser utilizadas para una mejor interpretación del PNB. La contabilidad de flujos de materia y energía (MEFA) (Eurostat 2001), la apropiación humana de producción primaria neta (Vitousek, Ehrlich et al. 1986; Haberl, Erb et al. 2001) y su combinación con el análisis Input-Output parecen candidatos prometedores para convertirse en algún tipo de indicadores de sostenibilidad (Haberl, Fischer-Kowalski et al. 2004). Sin embargo, pueden servir no tanto como medidas de bienestar, sino para interpretar mejor el PNB. El crecimiento económico en Chile, por ejemplo, es a menudo presentado como el resultado de modelo en términos de aplicación de las estrategias de desarrollo neoliberales. Un estudio realizado por Giljum (2004) estableció sin embargo un asunto a discutir, que Chile está alimentando su crecimiento económico mediante la explotación excesiva de sus recursos naturales y, de hecho, mediante el empobrecimiento de sí mismo. El marco MEFA y el análisis Input-Output podrían convertirse en herramientas importantes para establecer la escala óptima en términos de energía y volumen de producción de una economía, por lo que deben fundamental en el debate sobre el crecimiento.

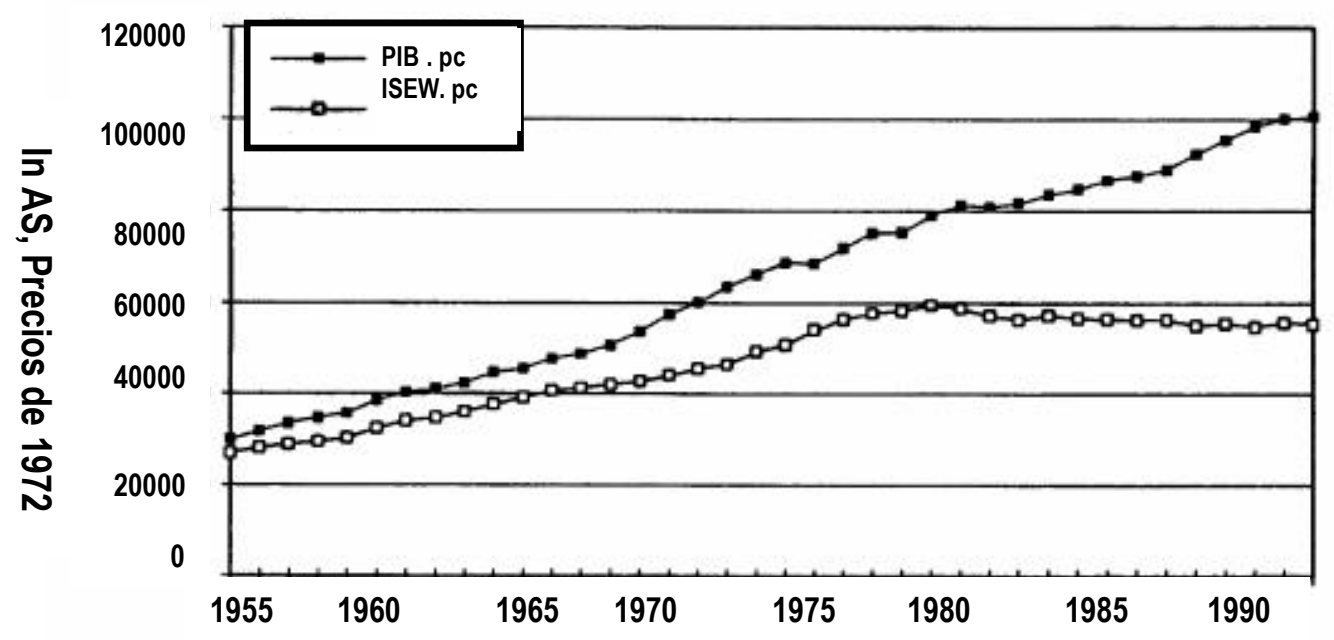

Figura 4: PIB y ISEW per capita de Austria 1955-1994 (extraido de: Stockhammer, Hochreiter et al. 1997, p. 30)

\subsection{Crítica física y socio-ética al crecimiento}

La definición estándar de los libros de texto de economía, según Daly (1992a), afirma que la economía es el estudio de la asignación de medios escasos entre finalidades rivales. "El objetivo de la asignación es la maximización del logro de esos fines." (Daly 1992, p. 18) Sin embargo, mucha confusión sobre el crecimiento económico, según el punto de vista de Daly (1992a), surge del hecho que el economista se centra exclusivamente en la gama media de su "espectro de medios-fines».

2 En términos de ISEW, Stockhammer et al. (1997) concluyen "mientras que el ISEW parece adecuado para destronar el PIB como indicador líder para la política económica, no está listo para usurpar dicho trono." (Stockhammer et al. 1997, p. 33) 
de medios finales" de Daly (1992a).

ignación de los medios intermedios (piezas, mano de obra) ón, confort, educación, etc). La Figura 5 ilustra el "espectro

Mientras que el lado derecho de la continua muestra los diferentes niveles en el espectro incluyendo algunos ejemplos, la izquierda indica la disciplina que tradicionalmente se ha mostrado más interesada en cada nivel. Cada nivel intermedio en el continuo es un fin en lo que respecta a categorías inferiores y un medio con respecto a niveles más altos. El fin último es, por lo tanto, logrado a través de los fines intermedios que a su vez se hacen posible a través del servicio del fin último. Sólo en los dos extremos se encuentra el final puro y medio puro. El fin último es tal que no se deriva su valor de ser un instrumento para el logro de ningún otro fin; es fundamentalmente bueno en sí mismo. En el otro extremo, los últimos medios son los medios que se utilizan para el servicio de fines humanos, pero a diferencia de medios intermedios no pueden ser creados por los seres humanos y, por lo tanto, no pueden ser el final de cualquier actividad humana.

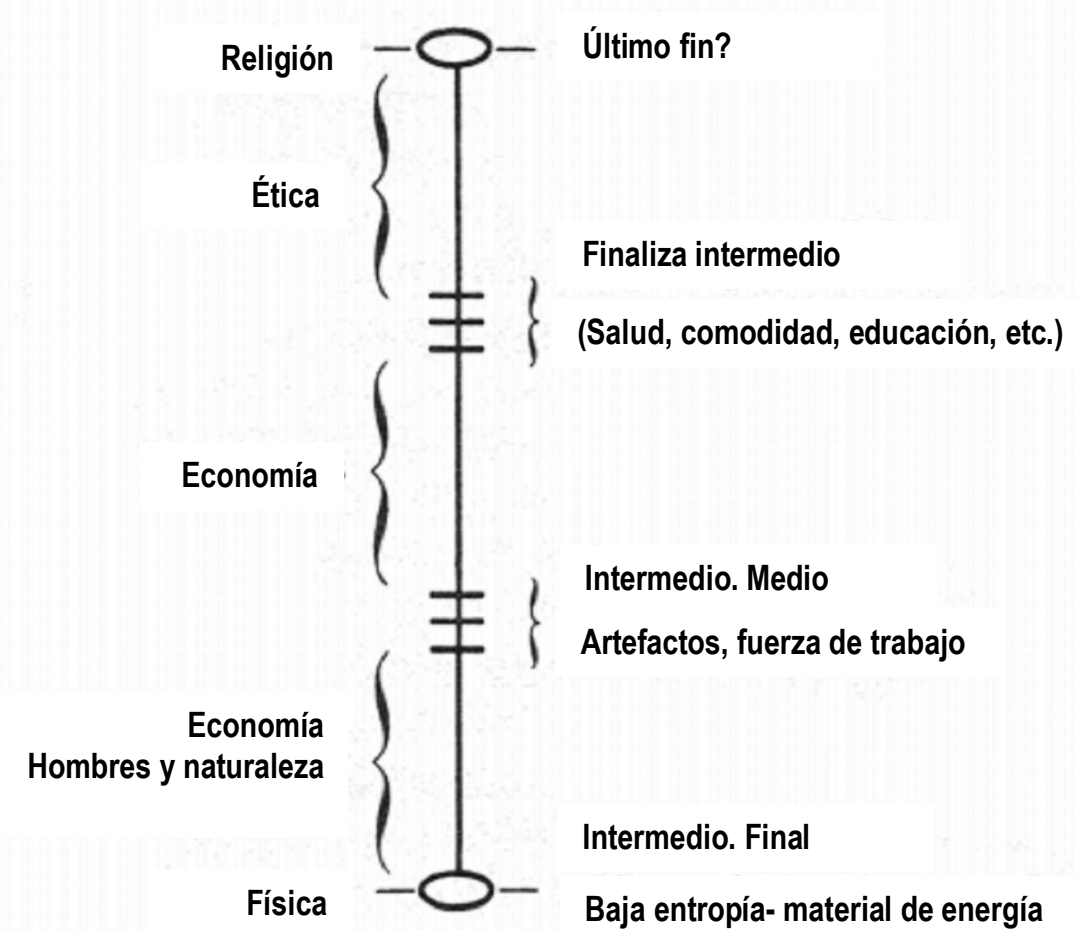

Figura 5: continuo de finalidades y medios de Daly (adaptado de: Daly 1992a, p. 19)

Por la simple concentración en los niveles intermedios del espectro, tradicionalmente los economistas no incluyen los límites absolutos en su estudio, ya que los límites absolutos, sólo pueden ser encontrados en última instancia. Esta negligencia de los fines últimos se traduce directamente en una falta de atención a la ética. Como se mencionó antes, debido a la adopción de 
nes éticas se convirtieron en una cuestión de preferencias jenos en los modelos económicos. Los medios últimos y los

límites absolutos a su disponibilidad, situados al otro lado del espectro de Daly (1992a), son igualmente ignorados por la corriente principal de la teoría económica. Se parte del supuesto que la tecnología puede casi ilimitadamente en última instancia transformar medios físicos (materia-energía de baja entropía) en medios intermedios.

El objetivo del crecimiento económico sin fin puede ser definido "como la conversión de cada vez más medios últimos en cada vez más medios intermedios (stocks de objetos), con el fin de satisfacer cada vez más finalidades intermedias, sean cuales sean." (Daly 1992, p.23) Por lo tanto, mirando solamente en los niveles intermedios del espectro fines-medios, los economistas llegaron a la conclusión de que, aunque cualquier deseo puede ser satisfecho, en conjunto son infinitos y nunca pueden ser satisfechos. De ello se deduce que en el fondo si los fines y los medios son ilimitados, el proceso de crecimiento puede continuar para siempre.

\subsection{Termodinámica y medios últimos}

Muy al contrario Nicolás Georgescu-Roegen (1971) sostuvo que sobre la base de la termodinámica, el crecimiento económico ilimitado es físicamente imposible. Los medios últimos son, en efecto, baja entropía ${ }^{3}$, la cual existe en la tierra en sólo dos formas diferentes: en stock terrestre y en el flujo solar. El stock terrestre se pueden dividir en aquellos recursos que son renovables en una escala humana de tiempo y aquellos solo renovables en una escala geológica de tiempo se conocen como no-renovables. Todas estas fuentes de baja entropía son absolutamente limitadas. Los no renovables como el petroleo son limitados en la cantidad disponible sobre la tierra mientras que los renovables son limitados en la tasa de explotación, aunque sean prácticamente ilimitados en términos de la cantidad total obtenida a lo largo del tiempo (Daly 992a). Un argumento similar puede hacerse para el flujo solar el cual es prácticamente ilimitado 4 en su cantidad total, pero estrictamente limitado en su intensidad y patrón de llegada a la tierra.

Aunque la materia y la energía no puede crearse ni destruirse, tal como la primera ley de la termodinámica afirma, ésta se transforma durante los procesos económicos de producción y consumo. Este proceso implica siempre la transformación de los estados de baja entropía en estados de alta entropía. Estados de materia organizados, estructurados y concentrados de baja entropía, por ejemplo, se convierten en productos básicos aún más estructurados y, a continuación, a través del uso, en estados dispersos, aleatorios, de alta entropía estados, en residuos. La energía

\footnotetext{
3. La entropía, es decir, técnicamente hablando una variable extensiva de estado (Baumgärtner 2003), que pueden definirse para cualquier sustancia o material de cualquier sistema (Ayres, 1998). Una variable extensiva de estado es una variable que es proporcional a las dimensiones de la red y que en cualquier momento, sólo depende del estado del sistema" (Baumgärtner 2003 p. 1) Masa o volumen son ejemplos, mientras que la temperatura o la presión serían ejemplos de variables intensivas. La segunda ley de la termodinámica establece que la entropía aumenta con cada acción física o transformación que ocurre en un sistema aislado, es decir, un sistema que no intercambia materia o energía con otros sistemas. Dentro de tal sistema o de hecho en todo el universo la entropía nunca puede disminuir, por lo que también ha sido llamado "flecha del tiempo"(Ayres 1998). El equilibrio de los sistemas internos se alcanza, cuando la entropía se maximiza (Ayres, 1998).

4. Es generalmente asumido que la fusión nuclear en el sol continuará por los próximos 4-5 mil millones de años (http://en.wikipedia.org/wiki/Sun)
} 


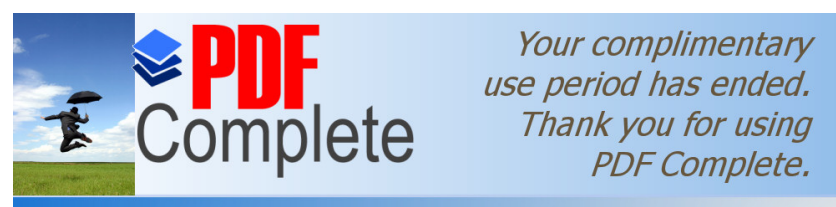

eeso de producción y consumo de los productos básicos. La lo, con un potencial para hacer el trabajo se convierte en energía de baja temperatura cuya capacidad de hacer el trabajo se pierde tan pronto como la temperatura se iguala con su medio ambiente circundante.

La fuente de baja entropía más abundante en el planeta es el flujo solar. Todos los combustibles fósiles del mundo quemados juntos sólo equivaldrían a unos pocos días de energía de la luz del sol (Daly 1992a). La cosa racional para la humanidad, por lo tanto, sería el uso de la mayoría de los recursos no renovables en la construcción de instalaciones para una mejor captura de la energía solar. Lo que ha sucedido, en lugar de ello, durante los últimos 200 años, es que la economía humana ha pasado a depender de los escasas formas disponibles de baja entropía - los minerales no renovables. Los optimistas tecnológicos a menudo argumentan que la tecnología moderna libera a la humanidad de la dependencia de los recursos (Barnett y Morse 1963; citado en: Daly 1992a). De hecho, más bien lo contrario. La tecnología, el deus ex machina de la economía neoclásica, sólo puede contribuir a un uso más eficiente de la corriente entrópica, pero no será capaz de invertir la dirección del flujo.

La razón por la cual esta marcada dependencia de los materiales terrestres no renovables crea la ilusión de más independencia es porque el hombre puede elegir la velocidad a la que hace uso de ella. El flujo solar, por otro lado, es limitado y sujeto a variaciones estacionales y diurnas. El rápido crecimiento económico, por lo tanto, es más fácil de lograr, al menos para un período de tiempo limitado, que con el flujo solar o recursos renovables. El resultado es el agotamiento del capital geológico y la sobrecarga de los ecosistemas con los nuevos materiales producidos para los que no existen los ciclos naturales (Daly 1992a). Según el espectro de fines y medios de Daly (Daly 1992a) la baja entropía es el "coste real", el coste de oportunidad en última instancia implicado en la satisfacción de fines. La baja entropía debe apreciarse en función de la valía de las mejores alternativas sacrificadas, ya que sólo puede ser utilizada para un fin (Daly 1992a).

\subsection{Fines últimos y sostenibilidad}

Los fines últimos son mucho más difíciles de definir que los medios últimos. Como mínimo, dejando consideraciones religiosas aparte, el fin último podría verse como la "supervivencia y la continuación del proceso evolutivo de la vida (Daly 1992a, p. 27) Esto no es más que una burda definición de la sostenibilidad. Söllner (1997), en su búsqueda de formas de integrar la termodinámica (el último recurso) en la teoría económica concluye que esta debe basarse en un valor de decisión explícito (fin último). La sostenibilidad es una decisión de esa índole. Sólo puede estar justificada por razones éticas y por lo tanto, no debe dejarse al mercado. Esta decisión debe ser seguida por las políticas ambientales específicas [(Ayres (1991, 1994), Binswanger (1993) Daly (1991), Georgescu-Roegen (1979); Hampicke (1992), Hyman (1980); Slesser (1993); todos los citados en: Söllner 1997)]. Esas políticas tendrían que incluir límites absolutos para la contención de la economía para que sea sostenible (Daly 1991; Daly 1992b, citado en: Söllner 1997).

El paradigma del crecimiento se apoya en las dos doctrinas de la relativa escasez de medios como se ha mencionado anteriormente y la insaciabilidad del deseo de satisfacer fines. La mayoría de 


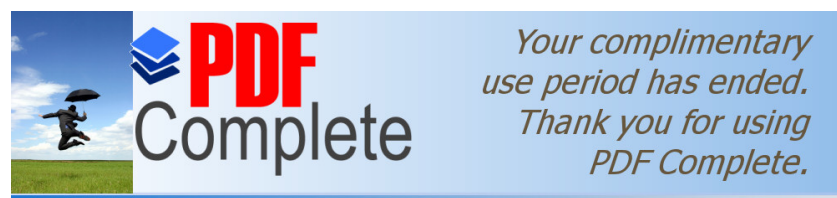

Click Here to upgrade to

Unlimited Pages and satisfechos por el crecimiento global (Daly 1992a). Por el y sus efectos secundarios parecen ser cada vez más el

camino. La satisfacción de algunas necesidades, como la necesidad de ocio, la contemplación, el silencio y la conversación, se hace más difícil debido al esquema producción-consumo. Existen ya algunos movimientos sociales locales, que promuevan el disfrute de un estilo de vida sencillo. Un grupo se llama a sí mismo "simplificadores voluntarios". Ellos voluntariamente reducen sus niveles de consumo con el fin de vivir una vida materialmente simplificada y forman parte de un movimiento mayor anti-consumo, que está en constante crecimiento(Zavestoski 2002)5.

Además no es cierto que todos los deseos son insaciables. John Maynard Keynes ((1963) 1997) distingue deseos absolutos y deseos relativos, sólo estos últimos se consideran ilimitado. En las sociedades opulentas la satisfacción de la mayoría de los consumidores deriva de tener algo que otra persona no tiene y no tanto del bien en sí. Los deseos relativos sólo se sienten cuando su satisfacción en sí misma sirve para distinguirse de los demás y hace que uno se sienta superior (Keynes (1963) 1997). O como John Ruskin (1986, citado en: Daly 1992a, p. 27) escribió: "el arte de hacerse usted mismo rico, en el ordinario sentido mercantil del economista, es igual y, por tanto, necesariamente al arte de mantener a su vecino pobre". Dado que no todos pueden ser relativamente mejores a todos los demás, los deseos relativos son indudablemente insaciables. Normativamente se puede argumentar que la búsqueda de deseos relativos, mientras que muchos otros siguen luchando para satisfacer sus necesidades absolutas (comida, vivienda, ropa, etc) es inadecuada. Además, debe cuestionarse si un modelo económico que exige que las personas estén insatisfechas es realmente beneficioso para la humanidad. La alternativa a una economía basada en la evidente necesidad del constante crecimiento es la economía del estado estacionario.

\subsection{La historia del estado estacionario (estado de equilibrio)}

Para la mayoría de la historia del hombre el crecimiento económico y los problemas asociados con él no fue un problema. Como se ha ilustrado anteriormente, la humanidad vivía en un mundo vacío hasta unos 50 años después del inicio de la revolución industrial a finales del siglo 18 y principios del 19. Antes de la revolución industrial la economía humana podía describirse como orgánica, es decir, no sólo los productos alimenticios, también la mayoría de los materiales utilizados para la producción se remontaban los recursos naturales orgánicos (bióticos) (Wirgley 1987; citado en: Luks 2001). A lo largo de los últimos 200 años esto ha cambiado hacia la economía de los minerales en la que vivimos hoy. La consecuencia más importante de este cambio es, por supuesto, la degradación del medio ambiente.

Dennis Meadows (Meadows 1977; citado en: Luks 2001) sostuvo que este fue el momento en que la humanidad abandonó la sostenibilidad y que antes el hombre vivía básicamente en sociedades en estado estacionario. Este argumento, sin cuantificarlo, es claramente falso. La historia de la humanidad está llena de ejemplos en los que las sociedades locales han superado la capacidad de sobreexplotación de los recursos renovables. También hay pruebas de que incluso los cazadores-

5 No obstante, a pesar de estos movimientos crecientes, la mayor parte de la gente todavía sigue patrones de consumo insostenibles y el nivel general de consumo sigue subiendo (Niemi 2006). 
menos del 0,01\% de la producción primaria neta (PPN) de

: Haberl, Fischer-Kowalski et al. 2004), contribuyeron importantemente a la extinción local de especies que eran sus presas preferidas (Sieferle de 1997, citado en: Haberl, Fischer-Kowalski et al. 2004). De igual manera las sociedades agrícolas, como en la antigua mesopotamia gradualmente degradó sus suelos debido a las técnicas de riego. Los campesinos tuvieron que abandonar primero la producción de trigo en favor de la cebada más resistentes a la sal y, por último, tuvieron que abandonar el cultivo de ambos (Haberl, FischerKowalski et al. 2004). Sin embargo, esto sólo significa que la historia de la humanidad no tiene a su fácil disposición modelos de estilo de vida sostenible. Esto no significa que no puede haber una alternativa de estado de estacionario al crecimiento económico.

\subsection{Los economistas clásicos}

Todos los economistas clásicos comparten el concepto de un estado estacionario causado por el crecimiento de la población y la disminución de los ingresos. Utilizan principalmente el estado estacionario como punto final ontológico del desarrollo económico y sólo algunos también como una ficción analítica (comparar el famoso capítulo de Ricardo comparar el famoso capítulo sobre el capital en forma de máquinas) ${ }^{6}$. El estado estacionario ontológico se ha definido como una referencia a la realidad económica, aunque esta realidad sólo se espera que se convierta en pertinente en un futuro distante. El estado estacionario se utiliza en "la noción de una economía cuyo punto final de desarrollo es aquel en el que la acumulación de capital ha cesado porque el beneficio se ha reducido a una tasa tan baja que no existe más incentivo para acumular capital" (Brandis 1989; citado en: Luks 2001).

El estado estacionario analítico, por otra parte, es una hipótesis que sirve sólo para fines analíticos (Luks 2001). Marshall (1961 [1890], citado en: Luks 2001), por ejemplo, describió el estado de equilibrio sólo como una "ayuda para hipótesis auxiliares". Debido a su simplicidad, la teoría del estado estacionario se utiliza como un primer paso para el análisis más complejo de una economía en desarrollo. El verdadero logro de tal estado es, sin embargo, considerado como "horriblemente realista" (Meade 1965, p. 25, citado en: Luks 2001, p. 29). Además, se puede distinguir entre la estacionariedad "positiva" y la "normativa (Luks 2001): En el primer caso la estacionariedad se alcanzará mediante una economía sin interferencias. En el segundo caso se refiere a la percepción de diversos autores como John Stuart Mill, mencionado anteriormente, y en la actualidad Herman Daly, que creen en la conveniencia de un estado estacionario (por ejemplo: por razones sociales 0 ecológicos).

Se supone (Robbins, 1930; citado en: Luks 2001) que la expresión de un estado estacionario se menciona por primera vez por Adam Smith (1723-1790), en "La riqueza de las naciones" (Smith 1776). Aunque sin duda sentó las bases del futuro paradigma del crecimiento, no creía que el crecimiento fuera posible indefinidamente. Esta fue una preocupación de Smith (1776), pues el

6 Esta afirmación es, por supuesto discutible: Kolb (1972), por ejemplo, insiste en que Malthus y Ricardo utilizaron el estado estacionario sólo como "un elemento de análisis en lugar de una visión de la realidad, porque en los términos de los horizontes temporales que Ricardo y Malthus creían que el estado estacionario era funcionalmente significativo no se consideran substanciales en el plano de la realidad" (Kolb 1972, p. 26, citado en: Luks, 2001, p. 141) 

subsistencia. En la estacionariedad los salarios y los beneficios deben ser bajos, lo que lo convierte en un estado "aburrido" (Smith, 1776, p. 99) para estar. Por lo tanto para Smith (1776) el estado estacionario es ontológico y equivalente a la disminución de los niveles de vida y, en general, a la pobreza.

Para Smith, la "bendición" del crecimiento económico sólo puede continuar hasta que un país ha alcanzado su "pleno complemento de las riquezas" (Smith, 1776, p. 99, citado en: Luks 2001). Esta situación se plantea tan pronto como el capital necesario es acumulado. El máximo nivel posible de la riqueza es a su vez determinado por la tierra y el clima del país. El crecimiento de "La riqueza de las naciones" (Smith, 1776) es, por tanto, una normalidad temporal, que puede continuar durante mucho tiempo, pero no para siempre. Aunque Smith considera la "apatía" de un estado estacionario inevitable en algún momento, su trabajo es generalmente considerado optimista, a diferencia de los escritos de Thomas R. Malthus (1766-1834).

Para Malthus, tanto el crecimiento ilimitado como un estado estacionario son imposibles. No comparte el optimismo de Smith por el progreso y estaba convencido de que "ninguna forma posible de sociedad puede evitar la casi constante acción de la miseria en una gran parte de la humanidad, en un estado de desigualdad, y sobre todo, si todos son iguales." (Malthus 1993 (1798), citado en: Luks 2001) Malthus llegó a esta conclusión a través de lo que llamó principio de población, que es la base de los actuales conceptos de capacidad de carga (Seidl Tisdell y 1999). Tres son los hechos básicos fundamentales de su teoría: en primer lugar el hecho de que la población humana aumenta exponencialmente $(1,2,4,16 \text {, etc })^{7}$. En segundo lugar la alimentación es necesaria para la existencia del hombre y es el único factor limitante del crecimiento de la población humana. Por último, alegó que la producción de alimentos sólo puede aumentar linealmente (1,2,3,4,5, etc.).

Para Malthus (1993 (1798)) estos tres hechos son la explicación de la escasez y la miseria que observó en Inglaterra en el momento. En su opinión hay dos controles que, naturalmente, limitan la población: por un lado hay la previsión de las dificultades identificadas con el establecimiento de una familia, que actúa como control preventivo. Por otro lado, "la angustia de algunas de las clases más bajas, por que no son capaces de proporcionar los alimentos y la atención adecuada a sus hijos, actúa como un control del crecimiento natural de la población."(Luks 2001, p. 111) los controles positivos aumentan la mortalidad (por ejemplo: las hambrunas, las plagas, guerras, etc), mientras que un control preventivo reduce la tasa de natalidad (por ejemplo: el aborto, el control de la natalidad, la prostitución, retrasar la edad de formación de nuevas familias, etc) (Gilbert 1993; citado en: Luks 2001).

Par Malthus, todos los controles, dan como resultado el vicio o la miseria, en la que la humanidad está condenada a vivir eternamente. En otras palabras, él predijo que la sociedad humana fracasaría continuamente en su intento de estabilizarse en el estado estacionario. En lugar de ello, constantemente rebasaría su capacidad de carga sólo para ser nuevamente diezmada por las

7 Curiosamente Malthus dedujo este crecimiento exponencial del aumento de población en América del Norte, no observado en otros lugares en ese momento y que fue en gran parte debido a la inmigración, un hecho que él ignora. No obstante, esta no afecta a la validez de la hipótesis de un crecimiento exponencial (Seidl y Tisdell 1999). 

sociedad (y Seidl Tisdell 1999), fue sorprendente influyente ${ }^{9}$. Incluso hoy sigue siendo importante para diversas disciplinas académicas.

Aunque Smith se concentró en las condiciones del crecimiento económico, con un interés centrado en los efectos de la división del trabajo, David Ricardo (1772 - 1823) centró su trabajo en los límites del crecimiento y en el análisis de la acumulación de capital y sus efectos sobre la distribución (Luks 2001). Su teoría de la distribución se basa en la escasez de tierras y su falta de homogeneidad en la calidad. Un aumento de la población fuerza la producción agrícola a expandirse hacia las tierras marginales con cada vez menos calidad. Que a su vez, requieren un esfuerzo cada vez mayor de mano de obra, que es la razón del aumento en el valor de los productos de la tierra. Como resultado de ello los ingresos de los productores de alimentos disminuyen, mientras que los precios de los alimentos aumentan. A continuación, los trabajadores necesitan salarios más altos, debido a que sus gastos aumentan con los precios de los alimentos. El aumento de los precios y los salarios, sin embargo, sólo puede continuar hasta que los salarios equivalen al total de ingresos del agricultor. A continuación, la acumulación debe llegar a su fin; "(...) ningún capital puede obtener ningún beneficio, y no se puede demandar más mano de obra adicional, y, en consecuencia, la población habrá alcanzado su punto más alto" (Ricardo 1817, citado en: Luks 2001, p. 119).

Esto significa que para Ricardo, no es la acumulación de capital la que conduce a una disminución de los beneficios, como alegó Smith, si no la conexión entre los beneficios y el coste de subsistencia. Subraya, sin embargo, que mucho antes de este estado de alza en los precios de los alimentos y bajos salarios, una tasa de beneficios tan baja ya ha eliminado el motivo para la acumulación del capital. La razón es que "(...) nadie acumula, si no es con la perspectiva de hacer su acumulación productiva, y eso es sólo así cuando opera con beneficios" (Ricardo 1817, citado en: Luks 2001, p. 120). Sin esta motivación para la acumulación de capital, el estado estacionario es inevitable (Ricardo 1817, citado en: Luks 2001). Sin embargo todos los escritos de Ricardo apuntan hacia el hecho de que a su juicio este estado estacionario sólo importa en un futuro distante. Creía que el comercio exterior podría prolongar la realización de el estado estacionario durante mucho tiempo 0 incluso indefinidamente (Ricardo 1817, citado en: Luks 2001).

John Stuart Mill (1806 - 1873) se considera a menudo como el último pensador importante en la tradición clásica (Welch 1989, citado en: Luks 2001) y es conocido como un fuerte crítico del (entonces) capitalismo existente. Fue no sólo economista, también filósofo y experto en ciencias políticas. Mill abogó por una separación de la producción y la distribución económica y para él las "leyes" se aplican únicamente a la producción y no a la distribución. (Schumpeter 1965 [1954], citado en: Luks 2001)

Al igual que Malthus, Mill está convencido de que las mejoras tecnológicas a la larga no podrán mantenerse con el crecimiento de la población, que se traduciría en una disminución de los niveles de vida. Es, por tanto, un proponente de medidas de control de la natalidad. (Mill 1965 [1948], citado

8 Véase la nota anterior.

9 Darwin, por ejemplo, afirmó que la obra de Malthus le inspiró en su trabajo sobre la teoría evolutiva (Barnet y Morse 1963, citado en: Luks 2001). 
que él postulan que un incremento en los niveles de vida aumento en el número de nacimientos, Mill esperaba que esto podría evitarse, por ejemplo, a través de la educación y el control de la natalidad. Esta esperanza es importante para comprender su optimismo con respecto a un estado estacionario, ya que en su opinión, sólo una población constante puede eliminar la permanente presión sobre los niveles de salarios ${ }^{10}$.

El factor limitante para el crecimiento económico según Mill es la tierra, pero al igual que Ricardo pensó que tal límite sólo sería pertinente en un futuro lejano (Mill 1965 [1948], citado en: Luks 2001). La cuestión de los límites es de una importancia definitiva para Mill que vio el abandono de estas cuestiones por parte de sus colegas no sólo como un error, si no "(como) el más grave, que se puede encontrar en todo el ámbito de la economía política" (Mill 1965 [1948], p. 173, citado en: Luks 2001, p 130) Sin un conocimiento profundo de estos límites a la producción, fijados por la finitud de la tierra y, por tanto, el medio ambiente natural, según Mill, no tiene sentido pensar en los problemas económicos (Mill 1965 [1948], citado en: Luks 2001).

Una vez que un país alcanza la tasa mínima de rentabilidad, a su juicio, no se puede dar ningún aumento adicional de capital y que el país alcanzará la estacionariedad (Mill 1888). El logro de la tasa mínima de rentabilidad depende de diversas condiciones, como la propensión a acumular y la seguridad de la capital. Aunque generalmente cambiante y difícil de identificar siempre existe un mínimo desde el punto de vista de Mill. Los países con altos niveles en las condiciones de vida están mucho más cerca de este estado que los países más pobres, a menos que los primeros estén dotados aún de grandes reservas de tierras fértiles sin desarrollar (Mill 1965 [1948], citado en: Luks 2001). El logro de este estado estacionario, por lo tanto, es una consecuencia de la gran cantidad de capital, que se acumula durante un período libre de crisis. El tiempo real necesario para lograrlo podría, no obstante, como sugirió Ricardo, prolongarse debido al progreso tecnológico y el comercio internacional (Mill 1965 [1948], citado en: Luks 2001)11.

Para Mill la consecución del estado estacionario como un punto final en el desarrollo económico, podría ser mucho más prolongada que para otros economistas clásicos. No obstante, espera que las futuras generaciones se "(...) contenten con ser estacionarias, mucho antes que la necesidad les obligue a ello" (Mill 1965 [1948], p. 756, citado en: Luks 2001 p. 138). Él "románticamente" pensó en ello como una condición en la que la humanidad habría cumplido sus necesidades esenciales y en los que podría centrar su atención en otras cuestiones, lejos de la agitada y tensa vida comercial y de objetivos económicos (Claeys 1987; citado en: Luks 2001), con una sociedad caracterizada por:

10 Se trata de una desviación de los escritos de Smith y Ricardo. (Luks 2001)

11 Llevando el argumento Mill más allá podría afirmarse que a fin de que continúe el crecimiento después de un cierto punto (es decir, cuando el progreso tecnológico no puede seguir el ritmo de crecimiento de la población), la economía de un país necesita de la adquisición de recursos otros países a través del comercio o bien la destrucción a través de crisis (guerras?). De ello se deduce que un país puede no sólo exportar e importar bienes, sino también sostenibilidad (Pearce, Turner et al. 1993; citado en: Luks 2001). Algunas regiones aparentemente ya "se encuentran en un déficit ecológico - su población se apropia de la capacidad de carga de otros lugares o de futuras generaciones" (Wackernagel y Rees 1994, citado en: Luks 2001). Alemania, por ejemplo, tendría que ser un par de veces más grande de lo que es, a fin de producir de todo lo consumido por su población. En otras palabras, Alemania "ocupa" tierras que pertenecen a otros estados (Schmidt-Bleek 1994, citado en: Luks 2001). Este fenómeno se conoce como intercambio ecológicamente desigual en el comercio (por lo general de norte a sur), y se discute ampliamente en otros lugares (por ejemplo: Hornborg 1998; Muradian y Martínez-Alier 2001); 

no sólo exenta de los trabajos más pesados, con suficiente tiempo libre, tanto físico como mental, también de los detalles mecánicos, para cultivar libremente la gracia de la vida, y ofrecer ejemplos de ello a las clases circunstancialmente menos favorecidas para su crecimiento. Este modelo de sociedad, tan preferible al presente, no sólo es perfectamente compatible con el estado estacionario, si no, al parecer, está más naturalmente vinculado a éste que a cualquier otro estado" (Mill 1888, p. 454).

El progreso económico, en lo que él llama la "sociedad progresista", con sujeción a un capital social creciente, el crecimiento de la población y el progreso técnico ("mejoras en la producción") no es satisfactorio para Mill (1888) y cuestiona las meta de tal progreso: "A qué punto final se dirige la sociedad con su progreso industrial? Cuando el el progreso cese, ¿en qué condiciones vamos a esperar que deje a la humanidad?" (Mill 1888, p. 453). El argumento claramente cambia de un carácter económico a otro ético, que es también evidente en las siguiente cita. Mill nos recuerda el hecho que el estado estacionario fue reconocido por casi todos los economistas de su tiempo:

"Ha sido siempre visto, más o menos claramente, por los economistas políticos, que el aumento de la riqueza no es ilimitado: que al final de lo que se llama el estado progresivo se encuentra el estado estacionario, que todos los avances en la riqueza no son más que un aplazamiento de esta, y que cada paso es avanzar hacia el estado estacionario.......) Esta imposibilidad en última instancia, evitar el estado estacionario - esta irresistible necesidad de que el arroyo de la industria debería finalmente dispersarse en un mar aparentemente estancado - debería haber sido, para los economistas políticos de las última dos generaciones, una desagradable y desalentadora perspectiva" (Mill 1888, p. 452).

Mill no comparte ese pesimismo en relación con el estado estacionario, por el contrario considera que es muy positivo y deseable:

"No puedo ... respecto al estado estacionario del capital y la riqueza con la aversión que por lo general se manifiesta hacia el por los economistas políticos de la vieja escuela. Me inclino a creer que sería, en su conjunto, una mejora considerable sobre nuestra situación actual. Confieso que no estoy encantado con el ideal de vida propuesto por aquellos que piensan que el estado normal de los seres humanos es el de luchar para conseguir algo, el pisoteo, aplastamiento, dar codazos, y pisarse los talones unos a otros que conforman el modelo de vida actual, son los más convenientes para la especie humana,si no los síntomas desagradables de la una de las fases del progreso industrial. (...) El mejor estado de la naturaleza humana es aquel en el cual, si bien nadie es un pobre, nadie desea ser más ricos, ni tiene ningún motivo para tema ser arrollado en los esfuerzos de los demás para empujarse hacia adelante a sí mismos " (Mill 1888, p 453).

En lo que se podría considerar como una especie de crítica cultural sobre el crecimiento, Mill dice que, en lugar del crecimiento, la distribución y el control de la población deben ser los objetivos principales:

"No sé por qué debe ser una cuestión de felicitarse que las personas que ya son más ricas que cualquiera necesite ser, hayan duplicado sus medios de consumir cosas que dan poco o ningún 
la riqueza. (...) Es sólo en los países atrasados del mundo icción un importante objetivo: en los más avanzados, lo que económicamente se necesita es una mejor distribución, y un elemento indispensable es una estricta moderación en la población" (Mill 1888, p. 454).

Para responder a uno de los primeros puntos de la crítica que normalmente se presenta contra el estado estacionario, afirma que tal condición es perfectamente compatible con el progreso técnico y sostiene que este progreso debe ser incluso estimulado:

"Apenas es necesario señalar que una condición estacionaria del capital y la población no implica un estadio estacionario de mejora humana. (...) Habría tantas posibilidades como siempre para todo tipo de cultura intelectual, y moral y el progreso social y, tanto espacio para mejorar el arte de vivir, y muchas más probabilidades de que sea mejorado, cuando la mente deja de ser absorbida por el arte de subir. Incluso las artes industriales como pueden ser cultivadas sinceramente y con éxito, con esta única diferencia, que en lugar de servir a ningún propósito, excepto el aumento de la riqueza, las mejoras de la industria producirían sus efectos legítimos, el de abreviar el trabajo" (Mill 1888, p. 454).

Este optimismo "romántico" sobre el estado estacionario es a menudo criticada como absolutamente utópico (Levy, 1987 [1981]; citado en: Luks 2001) e incompatible con las democracias capitalistas modernas. Se argumenta que la visión de Mill de un estado estacionario es el resultado de su "ingenuidad" de creer que el capitalismo es sólo un fenómeno transitorio, que, impulsado por su propia dinámica interna, pronto se transformara a si mismo. Al igual que Marx, Mill creía que tendría que darse un cambio fundamental en la sociedad para el tipo de nuevo orden social que él tenía en mente (Levy 1987 [1981], citado en: Luks 2001). A diferencia de Malthus y Smith, Mill creía en la capacidad de la sociedad para cambiar, un hecho que se considera su principal interés (Bladen 1974; citado en: Luks 2001).

Mill se sentía claramente atraído por las ideas socialistas (Levy, 1987 [1981], citado en: Luks 2001), sin embargo se desvinculó frente a la crítica socialista de la competencia. Sostuvo que no es el mejor incentivo, pero es absolutamente necesaria para el progreso social y que los límites artificiales a la competencia son erróneos (Mill 1888). Como declaró Levy, Mill esperaba que el estado estacionario fuera acompañado por una nueva, economía política post-capitalista, dominada por cooperativas de productores (Levy, 1987 [1981], citado en: Luks 2001) ${ }^{12}$.

Aunque la mayoría de economistas clásicos reconoció la prolongación de los efectos del progreso tecnológico en los límites al crecimiento (y por lo tanto en el estado estacionario), no tenían idea de los cambios introducidos por la revolución industrial que se acercaba. Economistas, durante y después de esta revolución, cambiaron radicalmente su visión. En Karl Marx (1818-1883), que es visto por muchos como clásico - o al menos ricardiano (Schumpeter 1965 [1954], citado en: Luks 2001), el capital y el trabajo pueden ya convertirse en los factores más importantes de la producción y la tierra pierde su importancia. Su concepto de estacionariedad (reproducción simple) es ya una

12 El autor contemporáneo Douglas Booth (1998) también promueve cooperativas de productores, como una manera de establecer un estado estacionario. Ve el crecimiento como la dinámica interna del sistema capitalista, por lo que el capitalismo en su forma actual no es compatible con un estado estacionario. 

de las obras de la mayoría de sus sucesores.

La "reproducción simple" de Marx (Marx, 1988 [1867], p. 592, citado en: Luks 2001, p. 143) describe una mera repetición del proceso de producción en el mismo nivel, lo que supone, básicamente, la inversión neta igual a cero. Ello describe una situación de equilibrio, lo que Marx cree que es inalcanzable para una sociedad capitalista.(Schumpeter 1993 [1942], citado en: Luks 2001), Sin embargo, tiene su propia visión ontológica del estado estacionario, pero sólo más allá del capitalismo en su idea del socialismo. Marx creía que en el socialismo "(...) la producción y los salarios reales aumentarían hasta el punto en que la sociedad decida, a través de algún mecanismo sin especificar, que ya es suficiente (...)." (Rostow 1990, p. 144, citado en: Luks 2001, p. 144) Al igual que Mill y mucho más tarde la versión del estado estacionario de Keynes, el sistema de Marx, se pone en un constante estado de equilibrio o la disminución relativa utilidad marginal y no por los rendimientos decrecientes.

El trabajo de Joseph Schumpeter (1883-1950) aunque no clásico debe mencionarse en este punto, al no ser ni un marxista (aunque a él le gustaba las ideas de Marx), ni neoclásico, ni un Keynesiano y estrictamente se opuso la formación de una "escuela schumpeteriana" (Luks 2001). Una cantidad considerable de su obra fue dedicada al estado estacionario, lo que él llama 'circulación'. En 'circulación' lo que se produce se consume en el mismo período y no hay ahorro, no hay beneficios ni capital, por lo que los créditos no son necesarios (Schumpeter 1952 [1911]; citado en: Luks 2001). La principal diferencia con respecto a su descripción de una economía en desarrollo sin embargo, es que tal vez crece (el crecimiento de la población y la riqueza), pero no se desarrolla. El desarrollo, en su opinión, sólo puede tener lugar si los emprendedores, a través de préstamos financiados por los capitalistas, empujan a través de nuevas combinaciones (Schumpeter 1952 [1911]; citado en: Luks 2001). (por ejemplo: nuevos productos, nuevos mercados, nuevas fuentes de energía, etc.)

Para Schumpeter el emprendedor es la clave para el desarrollo económico (Wienert 1990, citado en: Luks 2001) .. Si no hay más créditos disponibles, o hay un cambio repentino en el entorno, cuando ya no puede cumplir su función, entonces ese es el fin del capitalismo de Schumpeter (Luks 2001). Exactamente eso es lo que predice en su obra tardía "Capitalismo, socialismo y democracia" (Schumpeter 1993 [1942]), cuando su análisis ontológico se convierte en estado estacionario. El capitalismo se debe colapsar debido a su propio éxito, como "el el crecimiento y la prosperidad eventualmente paralizan el empresario y su deseo de innovar" (Allen, 1994, citado en: Luks 2001). Sin la "destrucción creativa" que causan, grandes empresas se especializadas tomarán su lugar y la innovación y el desarrollo se estancarán.

Según Schumpeter (1993 [1942]), este proceso de auto-destrucción del capitalismo finalmente allanaría el camino hacia el socialismo. "El proceso capitalista pone los objetos y las almas en forma para el socialismo" (Schumpeter 1993 [1942], p. 351, citado en: Luks 2001, p. 165). No obstante, lleva ello también a un estado estacionario? Schumpeter creía que el capitalismo no puede ser estacionario, lo que implica que una economía capitalista no podría ser estacionaria. Otros trabajos de Schumpeter apuntan también hacia esta hipótesis (Luks 2001). La predicción de Schumpeter para el futuro del capitalismo es, por tanto, similar a la de Marx - el capitalismo no puede sobrevivir a largo plazo (Schumpeter 1993 [1942], citado en: Luks 2001). 
mpoco se ajusta a la tradición neoclásica de rechazar el Unlimited Pages and E que Schumpeter, el interés por la estacionariedad sólo le empezó en una etapa avanzada de su vida, especialmente en las Posibilidades económicas para nuestros nietos (Keynes 1972a [1930]). Contrariamente a lo que la mayoría cree no era un fetichista del crecimiento, pero tenía su propia visión de un futuro como una agradable economía estacionaria basada por su ideal de una sociedad económicamente justa y que respete la libertad del individuo (Nolte y Schaaff 1994; citado en: Luks 2001). Keynes estaba convencido de que en los próximos cien años, el problema económico se resolvería (Keynes 1972b [1931], citado en: Luks 2001). El problema económico es el "(...) problema de la miseria y la pobreza económica y la lucha entre clases y naciones (...)" (1972b Keynes [1931], p. xviii, citado en: Luks 2001, p. 167) o de manera más general el problema de la escasez. Antes que ese estado pueda establecerse, sin embargo, Keynes predice una "revuelta nerviosa general" (Keynes 1972a [1930], p. 327; citado en: Luks 2001, p. 169), porque "la humanidad se verá privada de su tradicional fin" (Keynes 1972a [1930], p. 327; citado en: Luks 2001, p. 168) de luchar para resolver el problema económico.

El escenario de abundancia que describe en el estado estacionario se compara al de Marx; contiene elementos "románticos" similares al estado estacionario de Mill y recuerda a la crítica socio-ética del crecimiento de Daly. Según Keynes la acumulación de riqueza perderá su importancia (Keynes 1972a [1930], citado en: Luks 2001); el amor de posesión de dinero como un fin y un medio será reconocido como "algo repugnante y mórbido"(Keynes 1972a [1930], p. 329, citado en: Luks 2001, p. 169). Al igual que Schumpeter pensaba sin embargo, que el momento no había llegado todavía para una evolución de este tipo. Hasta entonces estos valores tan criticados tienen la importante función de guiarnos "fuera del túnel de la necesidad económica hacia la luz del día" (Keynes 1972a [1930], p. 331, citado en: Luks 2001, p. 170). Además, según Keynes (1972a [1930], citado en: Luks 2001) hay cuatro factores que determinan el momento en el que la luz al final del túnel se hará más visibles: el control del crecimiento de la población, la evitación de las guerras, el papel de la ciencia y la tasa de acumulación.

En lo que respecta a la función de la ciencia se refiere, parece en algunas declaraciones de Keynes que era muy optimista acerca de los avances tecnológicos, porque creía que el problema económico se resolvería mediante la acumulación de capital y las innovaciones técnicas. Además afirmó que el "nivel de vida en países progresará y en cien años será de entre cuatro y ocho veces superior a lo que es hoy" (Keynes 1972a [1930], p. 325f, citado en: Luks 2001, p. 168), o incluso superior. Aunque esto fue sólo escrito en 1930 el nivel de vida (que se define como la riqueza material) en los países industrializados podría ser ya cuatro veces o más alto ya hoy. En otras palabras, los escritos de Keynes dejan margen para interpretarlo como un optimista del crecimiento y tecnófilo, hasta que la humanidad alcance todas las riquezas que prometió.

\subsection{La teoría neoclásica del crecimiento}

Como ya se mencionó, el cambio de paradigma en la "revolución marginal" en la década de 1870 dio lugar a una destrucción del sistema clásico, según Schumpeter (1970 [1908]). Con Marshall el estado estacionario se convirtió en un instrumento de análisis y sólo el concepto ontológico de un estado estacionario fue rechazada (Luks 2001). Se argumentó que los economistas clásicos habían 
so tecnológico. Además Malthus y de Ricardo con respecto la población y la situación de los propietarios de tierras, respectivamente, no se confirmaron hasta un siglo después de su trabajo. Por lo tanto, se afirmó que "(...) los hechos empíricos que la moderna teoría del crecimiento trata de explicar son muy diferentes de las que la teoría clásica se enfrentaba" (Stiglitz y Uzawa 1969, p. 3, citado en: Luks 2001, p. 176).

Como resultado, el principio de población se convirtió en irrelevante a finales del siglo XIX debido a que el modelo de utilidad marginal podría incorporar cualquier hipótesis de tasas de natalidad y mortalidad, preferida por el autor (Schumpeter 1965 [1954], citado en: Luks 2001)13. De igual forma la tierra como factor de producción se convirtió en irrelevante ${ }^{14}$, en parte debido al creciente sector industrial (Perman, MA et al. 1996; citado en: Luks 2001) y la disminución de importancia de la agricultura en relación con la industria manufacturera (Stiglitz y Uzawa 1969; citado en: Luks 2001). Hoy en día la teoría neoclásica del crecimiento se centra en el capital y el trabajo como los únicos factores de producción. La tierra, el factor de crecimiento económico esencial en la economía clásica se "sustituye" por los avances técnicos para proporcionar la posibilidad teórica de crecimiento ilimitado (Stiglitz y Uzawa 1969; citado en: Luks 2001).

Los ensayos de Solow $(1956,1957)$ y Swan $(1956)$ son considerados como el inicio de la teoría neoclásica del crecimiento. Swan (1956, citado en: Luks 2001) describe un caso clásico caracterizado por un factor limitante de la producción: la tierra. En estas circunstancias, el capital debe crecer más rápido que el aumento de trabajo, a fin de mantener la producción per capita, frente a la disminución de los ingresos de la tierra. Dado que el capital crece más rápido que la producción, el beneficio disminuye continuamente. Dada esta situación, la economía tiende hacia un estado estacionario "clásico" (Swan 1956; citado en: Luks 2001). De ahí la inclusión de "(...) el progreso tecnológico, definido muy ampliamente para incluir mejoras en el factor humano, fue necesario para permitir el crecimiento a largo plazo de los salarios reales y el nivel de la vida." (Solow 1988, p. 313, citado en: Luks 2001, p. 179)

Con el supuesto que este progreso compensa la disminución del rendimiento, la economía tiende hacia un 'crecimiento estable en equilibrio "y no hacia un estado estacionario clásico (Swan 1956; citado en: Luks 2001). Este equilibrio, también conocido como "estado de equilibrio con crecimiento", se refiere "a modelos en los que la población y el capital son cada vez mayores absolutamente, pero que en determinadas proporciones entre magnitudes absolutamente crecientes permanecen constantes" (Daly, 1993, pág 366). Esto fue visto como más cercano a la realidad teniendo en cuenta el rápido crecimiento en de las economías industriales occidentales durante los cincuenta y sesenta. Con el progreso tecnológico y la asunción de la sustitución casi ilimitada de factores de producción, discutida ya anteriormente, se convirtió en el crecimiento ilimitado (en teoría) en posible.

\subsection{La economía del estado estacionario de Herman E. Daly}

Daly podría ser considerado como el "crítico del crecimiento" que proporciona a la sostenibilidad con

13 Se ha creado una disciplina separada, la demografía, que, sin embargo parece ser excluida del discurso de la sostenibilidad.

14 La incorporación de la tierra en el factor de producción capital es hoy en día una práctica común. 
xión (Luks 2001). Enlaza el debate sobre el crecimiento de Unlimited Pages and Expanded headows et al. 1972), con la reciente discusión sobre la sostenibilidad. Mientras el primero postula una reducción en el crecimiento económico, el sostiene únicamente una reducción del consumo de materiales y energía. Junto con Georgescu Roegen, de quien fue alumno Daly, y Boulding, es a menudo considerado como uno de los fundadores de la economía ecológica. La economía en estado estacionario (SSE, según sus siglas en inglés), para la cual Daly se considera el padre teórico, es considerada por muchos autores como uno de los pilares centrales de la estructura lentamente en desarrollo de la economía ecológica (Luks 2000). Algunos autores afirman incluso la equivalencia entre la economía ecológica y la economía del estado estacionario (Underwood y el Rey 1989, citado en: Luks 2000), mientras que otros, como el Daly 15 propio hablan de la equivalencia de este último con el desarrollo sostenible (Schröder 1995, citado en: Luks 2000). Esto, sin embargo, no significa que el concepto de SSE no sea indiscutible, todo lo contrario, es criticado por muchos por ingenuo y totalmente utópico (por ejemplo: Proops 1989; Luks 2001).

La visión del SSE de Daly fue inspirada por Malthus y Mill en particular, pero también por otros economistas clásicos. Él se ve a sí mismo como representante de una tradición clásica, y es la razón por la que destaca la utilización del término "estado de equilibrio" en un sentido clásico, refiriéndose a lo que Mill llamó "estado estacionario" (Daly 1981). John Stuart Mill utiliza el término "estado estacionario" para describir una economía en la que la población y el capital social han dejado de crecer. El nombre estado significa literalmente de pie o la estabilidad de algo (de la voz latina, a pie). El adjetivo estacionario (y constante) amplifica esta idea de pie en lugar de correr, de constancia en lugar de aumentar o disminuir (Daly 1981).

El uso del término estado estacionario se convirtió en problemático cuando los economistas neoclásicos lo redefinieron para referirse a una economía en la que los gustos y la tecnología son inmutables, pero en el que la población y el capital social podrían estar creciendo. Daly, por lo tanto, adoptó el término "estado de equilibrio" de las ciencias físicas y biológicas, dado que "el término significa para las ciencias físicas casi lo que el término estado estacionario significó para los economistas clásicos antes de la redefinición de lo neoclásicos" (Daly 1981, p. 366). Agregando confusión sobre la terminología existe el término "estado de crecimiento en equilibrio", ya mencionado anteriormente, definido por teórico del crecimiento neoclásico teóricos como Hahn y Matthews (Hahn y Matthews, 1964; citado en: Luks 2001). Incluso se convirtió en un concepto central en la teoría neoclásica del crecimiento, Stiglitz y Uzawa (1969, citado en: Luks 2001).

\subsection{La visión pre-analítica}

La visión de Daly sobre el concepto del estado de equilibrio se basa en dos magnitudes físicas: el stock de capital (de personas y objetos) y el flujo físico de throughput (materia y energía) (Daly 1992). Las dos poblaciones físicas de personas y objetos se caracterizan por la prestación de servicios por un lado, y que requieren mantenimiento y sustitución por otro. El stock de objetos depende directamente del número de personas, ya que son considerados como "extensiones del

15 Daly, por ejemplo, habla de "economía sostenible o estado estacionario." (Daly 1996, p. 149) 

los seres humanos a otros (médicos, carpinteros ,...) y/o a ellos mismos.

Sin embargo, los objetos se desgastan y deben ser reparados o reemplazados y las personas necesitan alimentos, calentarse, etc, y eventualmente, morir. Por lo tanto hay un flujo continuo a través de la producción y el nacimiento y la correspondiente salida a través de la depreciación y la muerte de estas dos poblaciones. Este mantenimiento y reemplazo de artefactos y cuerpos humanos requerirá un throughput de materia y energía. Este throughput se inicia con la recolección de las fuentes de la naturaleza útiles de baja entropía (recursos naturales) y termina con la contaminación de la naturaleza con los sumideros de residuos de alta entropía (residuos, contaminación y calor residual) (Georgescu-Roegen 1976, citado en: Söllner 1997).

Desde esta visión general Daly (1992a, p. 17) deduce de su definición de la SSE17 "orientada al stock" que describe como: "(...) una economía con las poblaciones de personas y objetos constantes, mantenidas a un nivel deseado, suficientemente bajo, de throughput de mantenimiento, es decir, los flujos de materia y energía más bajos posibles a desde la primera etapa de la producción (la recolección de los materiales de baja entropía del medio ambiente) hasta la última fase de consumo (la contaminación del medio ambiente con residuos de alta entropía materiales exóticos )". Daly (1992a) destaca que la SSE es un concepto físico. Lo que se mantiene constante, por lo tanto, es stock de capital, en el más amplio sentido físico del término. Algunas magnitudes no físicas como la cultura, el conocimiento, la bondad, los códigos éticos, etc. no se mantienen constantes. En otras palabras, una SSE es una economía que se desarrolla aunque no crezca físicamente. Tal como se expuso anteriormente el PNB suma throughput, el incremento de stock de capital social y los servicios generados por este stock de capital. Por lo tanto, es irrelevante para la definición anterior. Una gran parte de este refleja el throughput y, por lo tanto un coste, por lo que una reducción del PNB en una SSE es totalmente posible y aceptable, si es una consecuencia de la reducción de los "costes".

Si bien la base teórica para el capital en la SSE proviene de Lotka (1956), como se mencionó anteriormente, el concepto renta se remonta a Fischer (Fischer, 1906; citado en: Daly y Cobb 1989) "(...) que una adecuada contabilidad de la renta sólo debe reflejar el flujo de servicios de capital que se gozan en el flujo de la conciencia subjetiva de las personas, durante un período de tiempo." (Daly 1992, p. 36) Para poner un ejemplo, la compra de un piano este año no forma parte de la renta de este año, sino que incrementa el capital. Por otro lado las rentas de este año son solamente los los servicios prestados durante todo el año mediante la producción de música.

Las transacciones intermedias, que impliquen el intercambio y la transformación física de los bienes, de acuerdo con Fisher, se anulan, dejando únicamente, según Fisher, el "margen no cancelado" de

16 Lotka (1956) postula la visión del capital como "órganos exosomáticos". Por ejemplo, ropa y casas amplian nuestra piel, estufas, utensilios de cocina y alcantarillado extenden el tubo digestivo, las bibliotecas y los ordenadores ampliar el cerebro y así sucesivamente.

17 Al comienzo de la década de 1990, Daly ha pasado más de una definicíon del estado de equilibrio "orientada al stock" a otra "orientada al flujo", que sin embargo no varía en sus objetivos económicos. En él una economía en estado de equilibrio se describe como una economía "cuyo caudal se mantiene constante en un nivel que no agota el medio ambiente más allá de su capacidad regenerativa, ni contamina más allá de su capacidad de absorción." (Daly 1992, citado en: Luks 2000, p. 46). 
física neta, que ve como el beneficio neto final de la actividad económica.

Sin embargo, no incluye el coste real final, contra el cual se debe comparar el valor final de la renta física neta. Daly, por lo tanto, complementa la renta de Fisher con el concepto físico de los costes reales elaborado por Kenneth Boulding (1966) y de Nicholas Georgescu-Roegen (1971). Estos costes son inevitables debido a que el stock de capital se deteriora y debe ser reemplazado (véase más abajo la cuarta ley de Georgescu-Roegen). Después de estas aclaraciones las tres magnitudes de la SSE según Daly, pueden resumirse del siguiente modo:

\begin{tabular}{|c|c|}
\hline STOCK & $\begin{array}{l}\text { "El inventario total de los bienes de producción, los bienes de consumo y los } \\
\text { cuerpos humanos. Ello corresponde a la definición de capital de Fisher (1906, } \\
\text { citado en: Daly 1992a) y pueden entenderse como el conjunto de todas las } \\
\text { cosas físicas capaces de satisfacer los deseos humanos y estar sujetas a la } \\
\text { propiedad." (Daly 1992, p. 35) }\end{array}$ \\
\hline SERVICIOS & $\begin{array}{l}\text { "La satisfacción experimentada cuando se satisfacen las necesidades , o "la } \\
\text { renta física" en el sentido de Fisher (1906, citado en: Daly 1992a). El servicio } \\
\text { es dado por el stock. La cantidad y calidad del stock determinan la intensidad } \\
\text { de los servicios." (Daly 1992, p. 35) No hay unidades para medir los servicios, } \\
\text { por lo que es discutible si pueden ser realmente una «Magnitud». Sin } \\
\text { embargo, todo el mundo puede y está experimentando un servicio o una } \\
\text { satisfacción y puede reconocer las diferentes intensidades de la experiencia. } \\
\text { Aunque el servicio es dado a través de un período de tiempo y, por tanto, } \\
\text { parece ser una magnitud de flujo, no puede ser acumulado como si se puede } \\
\text { con otros flujos. Por lo tanto es probable que sea más preciso pensar en los } \\
\text { servicios como un flujo físico (Georgescu-Roegen 1971, citado en: Daly } \\
\text { 1992a). Los servicio son el beneficio económico último de la actividad } \\
\text { económica. }\end{array}$ \\
\hline THROUGHPUT & $\begin{array}{l}\text { El flujo físico entrópico de materia y/o energía desde las fuentes de la } \\
\text { naturaleza a través de la economía humana, y de vuelta a la naturaleza a } \\
\text { través de los sumideros y que es necesario para el mantenimiento y la } \\
\text { renovación los stocks" (Boulding 1966; Georgescu-Roegen 1971; Daly } \\
\text { 1992a, p. 35)" El flujo de throughput no proporciona servicios directamente, } \\
\text { sino que deben ser acumulados y transformados en stock de artefactos útiles } \\
\text { (capital)." (Daly 1992, p. 36) }\end{array}$ \\
\hline
\end{tabular}

Cuadro 1: definiciones de Daly de Stock, servicios y throughput (adaptado de: Daly 1992a, p. 36)

Volviendo a la discusión sobre la escala óptima de una economía, esta podría definirse como aquella en la que se maximiza el servicio total, desde la economía y el ecosistema. Según Daly (1992a, p. 35) "Esto sucederá cuando el incremento de servicios fruto de un incremento marginal de stock sea igual al deterioro de los servicios derivados de los servicios de los ecosistemas que se derivan del incremento del throughput requerido por el incremento del stock." Por las razones ya mencionadas anteriormente podría no ser apropiado tratar de calcular este óptimo. En su lugar, Daly (1992) aboga 
p. 35) La identidad siguiente ilustra las interrelaciones entre las tres magnitudes de Daly:

\begin{tabular}{|l|l|}
\hline Identidad de Daly & Servicios / throughput = servicios/stock * stock/throughput \\
\hline Ratio & \multicolumn{1}{|c|}{$(1)$} \\
\hline Medida de eficiencia & $\begin{array}{l}\text { (1) Eficiencia de los servicios respecto el throughput. } \\
\text { (2) Eficiencia de los servicios-stock. } \\
\text { (3) Eficiencia del mantenimiento del stock }\end{array}$ \\
\hline Límites & $\begin{array}{l}\text { (1) ---- } \\
\text { (2) posibles: sistema nervioso humano y tiempo } \\
\text { (3) segunda ley de la termodinámica }\end{array}$ \\
\hline
\end{tabular}

Tabla 2: Stock, servicios y throughput y sus interrelaciones (adaptado de: Daly 1992a, p. 36)

Los stocks de capital son centrales en el análisis de Daly, ya que son magnitudes intermedias throughput acumulado, congelado temporalmente en estructuras ordenadas. Por un lado, presta servicios (relación 2), por el otro lado se necesita throughput para el mantenimiento (relación 3). Los stocks de las relaciones (2) y (3) se anulan de la misma manera que se desgastan en el mundo real. El beneficio último que queda es por lo tanto, el servicio, no los stocks y el coste final del servicio es el throughput, o mejor dicho, el sacrificio de los servicios de los ecosistemas provocado por el throughput. "El stock no es ni una ventaja ni un coste, pero los beneficios y los costes son funciones de los stocks."(Daly 1992, p. 37)

Cada una de las tres dimensiones requiere un tratamiento diferente en el paradigma de estado estacionario de Daly (1992a). El nivel de stock debe ser satisfactorio, lo que significa que debe ser elegido, para que sea suficiente para una buena vida y sostenible durante un largo futuro. El throughput por otro lado debe reducirse al mínimo, siempre que el mantenimiento constante de los stocks y los servicios sea máximo, con sujeción mantener constante los stocks. Como se indica en el cuadro 2, la proporción (1) representa la eficiencia final de los servicios es decir, el beneficio final respecto los costes finales, la ratio (2) representa la eficiencia de los servicios respecto los stocks, y la relación (3) la eficiencia de mantenimiento del stock respecto al throughput empelado. El desarrollo económico en términos de estas relaciones se define así como el aumento de los coeficientes (2) y (3) y, por tanto, conseguir que un mayor número de servicios de cada unidad de throughput. El crecimiento económico por otro lado, significa aumentar los servicios mediante el aumento del tamaño de los stocks, pero sin aumentar (o incluso disminuir) las ratios de eficiencia 2 y 3. Por lo tanto, una economía en estado de equilibrio pondría fin al puro crecimiento, manteniendo los stocks constantes y no reduciría, sino estimularía el desarrollo (Daly 1992).

Aunque la proporción (3), según Daly (1992a), se encuentra limitada por la segunda ley de la termodinámica, los límites para la relación (2) (eficiencia de los servicios) son menos claros. Se podría argumentar que no hay límites a la cantidad de servicios derivados de un determinado nivel de stock. Por otra parte, como se ha mencionado anteriormente, en un cierto nivel, un incremento de stock valores sólo puede venir en forma de bienestar. Por otra parte, podrían considerarse los límites 
plo, el ojo humano no reconoce a una nueva mejora de la Unlimited Pages and Expannoled na cierta cantidad de píxeles por pulgada. Tiempo también podría ser mencionado como un límite en el sentido de que alguien que posee una cancha de tenis y luego compra un club de golf, tendrá menos tiempo para el tenis, pues cuantos más aparatos posee menos tiempo uno tiene para cada uno de ellos, estableciendo así un límite a los servicios derivados de ellos.

Estas consideraciones nos llevan a la cuestión, que nivel de stock es suficiente? Esta pregunta es inherente al discurso de la sostenibilidad. Si se adopta la definición de sostenibilidad de Brundtland (WCED 1987), se plantea un problema sobre la definición de las necesidades. A menudo se argumenta que no hay razones para defender la SSE si no sabemos cual es exactamente el nivel óptimo de stock. Según Daly (1992a) se trata de un argumento falaz por dos razones: en primer lugar la estabilidad y la viabilidad son más importantes que la optimalidad. Dado que los niveles reales de la población y los objetos vienen determinados históricamente, la humanidad debe primero aprender a ser estable y, a continuación, preocuparse por la optimalidad. En segundo lugar, como se ha mencionado al principio de este documento, las pruebas de los distintos ámbitos de investigación muestran que los límites de expansión de los ecosistemas ya se han alcanzado. Según algunos autores el nivel óptimo ya fue superado en la década de 1970 (Meadows, Meadows et al. 1972; Daly 1992a).

\subsection{Las tres instituciones para el SSE de Daly}

Daly (1992a) insiste en la necesidad absoluta de un estado de equilibrio, y proporciona un concepto de apariencia sólida y global para alcanzar dicho objetivo. Esto incluye también tres recomendaciones institucionales concretas. Sin embargo, Daly (1992a) señala que podría haber otras instituciones que podrían ser más apropiadas. Las tres instituciones se basan en dos fundamentos económicos ampliamente establecidos: el mecanismo de precios y la propiedad privada, pero Daly (1992a) los extiende a zonas donde no se aplicaban anteriormente: el control total de los nacimientos y el control del throughput global. Habida cuenta de la definición anterior del SSE existe una necesidad de (1) una institución para la estabilización de la población, (2) una institución para la estabilización de la población de objetos físicos y de mantenimiento del throughput por debajo de los límites ecológicos, y (3) una institución redistribuiva capaz de limitar el grado de desigualdad en la distribución de un stock constante entre la población.

En primer lugar, y esta es posiblemente la más controvertida sugerencia, Daly (1992) aboga por licencias de nacimiento transferibles, tal como las presentó Kenneth Boulding (1964). El plan de Boulding combina la macro-estabilidad con la micro-variabilidad y sugiere que a cada mujer ${ }^{18}$ se le debe proporcionar una cantidad de licencias reproductivas que corresponde a la tasa de fecundidad de reemplazo (o menos si fuera necesario una reducción de la población). Por lo tanto, recibirían 2,1 licencias cada una. Las licencias se podrían dividir en unidades de una décima, donde diez unidades dan el derecho legal a un nacimiento. Las licencias son transferibles libremente mediante venta 0

18 Sólo a la mujer, porque las mujeres son el factor limitante en la reproducción y la maternidad, y además es más demostrable que la paternidad (Daly 1992). 

recibido con escepticismo y rechazo, que sin embargo no se detallará aquí.

Una segunda institución es la de limitar el grado de desigualdad y el tamaño y el poder de monopolio de las empresas. Esto se conseguirá a través de límites mínimos y máximos sobre la renta y un límite máximo de riqueza ${ }^{19}$. No hay casi ningún razonamiento económico detrás de esta propuesta. Daly (1992a) se limita a afirmar que las demás instituciones no serán aceptadas sin esta; la propiedad privada y toda la economía de mercado perderían su base moral y la conveniencia de ampliar el mercado para cubrir el nacimiento y las cuotas de recolección no serían lo suficientemente fuertes (Daly 1992). En ausencia de grandes concentraciones de renta y riqueza, el ahorro sería menor, ya que realmente representaría abstinencia de consumo en lugar de superávit restante después de la saciedad (Daly 1992). Esto apoyaría la estabilidad, porque menos presiones para la expansión de grandes cantidades de excedentes que cada vez buscan nuevas formas de crecer de forma exponencial y, por tanto, causando crecimiento, ya sea físico, inflación, o ambos (Daly 1992).

Es importante mencionar en este punto que el SSE de Daly (1992a) no está motivado por una ideología de izquierdas. Se basa en premisas conservadoras (de propiedad privada, el libre mercado, la oposición a las burocracias del bienestar y el control centralizado), sino que también sigue la consigna de "poder para el pueblo" ya que según Daly (1992a, p. 55): "(...) Se pone la fuente del poder, es decir, la propiedad, en manos de las muchas personas y no en manos de los pocos plutócratas capitalistas y socialistas burócratas ". Daly (1992a) subraya continuamente que su enfoque no es ni de izquierda ni de derecha, y pide a los políticos y economistas a dejar de pensar exclusivamente en estas dos direcciones.

Por una parte, la proposición de una institución de ese tipo podría ser muy atractiva, pero de manera intuitiva, por otra parte, es claramente el componente más débil en la base teórica en la Daly (1992a). Una variedad de cuestiones problemáticas no se abordan, como la manera de hacer frente a la acumulación dentro de la familia, es decir: la herencia, el papel de las sociedades anónimas y sus accionistas y la posible cesación de incentivos empresariales.

Como se ha afirmado anteriormente el precio de mercado sólo puede ocuparse de la escasez relativa, no de la escasez absoluta. Por lo tanto las cuotas de recolección física se presentan como la tercera institución de la SSE. Debido a la ley de la conservación de la materia y la energía, un límite en el agotamiento total - es decir, una imposición de un control sobre los flujos de throughput también indirectamente limita la contaminación global. Un límite al flujo de throughput por otro lado, indirectamente, también limita el tamaño del stock mantenido por estas. A diferencia del enfoque de final de tubería adoptado en el Protocolo de Kioto (CMNUCC 1997) 0, como se propone Booth (1998), Daly (1992a, p. 56) insiste en que "[la] entropía está en su mínimo en la boca de entrada (recolección) de la tubería del throughput y en su máximo en la salida (la contaminación) final. Por lo tanto, es físicamente más fácil de supervisar y controlar el agotamiento de los recursos que la contaminación - hay menos minas, pozos, y puertos que chimeneas, vertederos de basura y

19 Como la riqueza y los ingresos son en gran medida intercambiables, un límite en ambos es necesario (Daly 1992). Además, la concentración de la riqueza, según Daly (1992a), se convierte en incompatible con una economía de mercado y la democracia política. 
as difusas fuentes de emisión, como el escurrimiento de en los ríos y los lagos o los escapes de automóviles."

Esta es una crítica directa a las políticas medioambientales neoclásicas de "internalización de las externalidades" aplicadas a los impuestos Pigouvianos y otros instrumentos de política sobre la base del principio "quién contamina paga". El problema con estos impuestos es que no necesariamente limitan el throughput global, por las siguientes razones: si bien es cierto que el precio más el impuesto determina la demanda en una determinada curva de demanda (suponiendo que los encargados de formular políticas conocen su elasticidad), los cambios en estas curvas están sujetos a grandes errores de estimación, incluso aunque sean estables (Daly 1992). Un cambio en la curva de demanda de un recurso, por ejemplo, podría ser inducido por un aumento de la población, cambio de preferencias, aumento de la renta, etc. Si, por ejemplo, la gasolina fuera gravada con mayor intensidad esto podría tener dos efectos, que no necesariamente darían como resultado una menor utilización de los recursos. Las personas podrían utilizar menos sus automóviles y a cambio andar en bicicleta o utilizando el transporte público (más barato), sino que tal vez deciden gastar el dinero que ahorran en otros bienes intensivos en recursos - el llamado efecto rebote (véase, por ejemplo: Hertwich 2005). Y en segundo lugar, la gente podría simplemente cambiar la composición de sus presupuestos - es decir, seguir utilizando el coche tanto como antes, pero gastando menos dinero en otro consumo o en ahorro ${ }^{20}$. Además los efectos de un impuesto pueden ser compensados por una expansión del crédito por parte de la banca, un aumento de la velocidad de circulación del dinero, 0 el gasto público por parte del gobierno para otros fines (Daly 1992). Los impuestos son, por tanto, no adecuadas para limitar el throughput total (Daly 1992).

De hecho, los impuestos a la contaminación podrían dar lugar a un aumento en el throughput. Las industrias de extracción de recursos pueden implementar tecnologías más eficaces para aumentar la recolección, a fin de volver a ser competitivas. Muchos países en desarrollo dependen en gran medida de las exportaciones de uno de sus recursos naturales (por ejemplo: Chile y el cobre). Si reciben un aumento de la competencia por parte de la industria del reciclaje, que en última instancia, se beneficia de los impuestos a la contaminación, podrían verse obligados a extraer más, a fin de evitar una disminución de los ingresos. No obstante los impuestos a la contaminación son útiles, pero sólo para un ajuste a nivel micro (por ejemplo: para la regulación de una industria en particular). En el nivel macro alguna forma de cuotas sería más eficaz en la reducción del throughput total.

Daly describe el mercado de recursos en su SSE en dos niveles. El gobierno en primer ejerce un monopolio en la subasta de derechos de cupo limitado a muchos compradores. Estos compradores de recursos, después de haber comprado las cuotas de derechos, entonces encuentran muchos vendedores de recursos en un mercado competitivo. El precio de mercado de los recursos tiende a la igualdad de los costes marginales y los productores más eficientes ganan rentas diferenciales. Las rentas de escasez puras resultantes en las cuotas, se capturó en el mercado de subasta de cuotas por parte del monopolio del gobierno (Daly 1992). Esta renta inesperada podría utilizarse para financiar la renta mínima de la institución redistributiva, como se ha mencionado anteriormente. Ese

20 Los impuestos sobre los combustibles son, por ejemplo, en el Reino Unido (766€ por 1000 litros) casi dos veces mayor que en Alemania (€ 440 por 1000 litros), que tiene los segundos impuestos sobre los combustibles más elevados de la Unión Europea (Foro Ökosoziales Österreich 2003) Sin embargo los británicos se encuentran entre los usuarios más intensivos de automóviles en Europa. 
El efecto directo de esta política sería que la contaminación se reduciría al disminuir el throughput total tal como la primera ley de la termodinámica predice (Ayres, 1998). Indirectamente, todos los productos probablemente serían más caros, pero principalmente los que utilizan muchos de los recursos limitados. Esto fomentaría el cambio a bienes menos intensivos en recursos, el reciclado y la inversión en tecnologías de ahorro de recursos y métodos para la captura de la energía libre del sol de manera más eficaz. Las cuotas también pueden utilizarse para imponer un tamaño máximo de empresa, para no permitir que una sola entidad tenga la propiedad de más de un $\mathrm{x}$ por ciento de la cuota de derechos de un determinado recurso o más de un porcentaje y de los recursos propiedad de la industria a la que pertenece. X e Y podrían ser fijados para permitir economías de escala. (Daly 1992a)

Las cuotas al principio se fijarían en los niveles actuales de consumo de recursos, pues la primera tarea consiste en estabilizar el sistema y cesar el aumento en el uso de los recursos. Entonces debería tratarse de reducir las cuotas a un nivel más sostenible a fin de evitar la excesiva contaminación y los costes ecológicos para las generaciones presentes y futuras. Para los recursos renovables las cuotas deben establecerse a un precio razonable teniendo en cuenta algunos cálculos del rendimiento sostenible máximo. Las cuotas para los no renovables, por otro lado reflectirían el juicio puramente ético en términos de cuántos recursos deberían dejarse para las generaciones futuras - una decisión que el mercado no puede hacer porque las generaciones futuras no pueden presentar ofertas en los mercados de recursos.

En resumen el concepto de SSE de Daly (1992a) utiliza la eficiencia distributiva del mercado para (1) la asignación del conjunto de recursos limitados entre las empresas competidoras; (2) la reasignación de las licencias de partidas de nacimiento, después de que hayan sido distribuidas inicialmente por igual entre todas las personas y (3) la distribución de los ingresos dentro de los límites máximos y mínimos. La combinación de las tres instituciones ofrece, según Daly (1992a), una buena conciliación de la eficiencia y la equidad, mientras que al mismo tiempo proporciona el ambiente necesario de control macro del crecimiento, con el menor sacrificio en términos de nivel micro de la libertad y la variabilidad. El mercado puede circular libremente dentro de las fronteras de los impuestos ecológicos y los límites éticos.

\subsection{Crítica a la SSE: Utopía y crecimiento moral}

Para la mayoría de la gente el concepto de SSE de Daly (1992a) es simplemente una utopía y él mismo admite que en el corto plazo probablemente no es una opción. Sin embargo, en el largo plazo, si las personas apostaran por él debido a la degradación del medio ambiente y el problema de la superpoblación se hiciera más evidente y si hubiera el necesaria crecimiento moral, entonces la causa puede prosperar (Daly 1992). El hecho de que Daly (1992a) se base en gran medida en este "crecimiento moral"21 en la sociedad ha llevado a algunos autores a sugerir que podría haber

21 Daly (1992a) nombra conjuntamente cuatro principios básicos morales sobre los que construye su concepto del estado estacionario: algún 

2001). Daly la (1992a) responde que la ciencia se sigue obsesionado con el positivismo y las declaraciones acerca de los valores morales o la ética en las ciencias sociales siguen siendo tabú. En la búsqueda científica de sofisticadas resoluciones mecánicas y tecnológicas", (...) las apelaciones a las soluciones morales y a una corrección de los valores se considera como una admisión de la derrota intelectual, como un retiro de las reglas del juego - como hacer trampa" (Daly 1992, p. 47). Además, podría sostenerse que "las actitudes de siempre más, después de mi el diluvio, técnica y arrogancia"(Daly 1992, p. 47) son también las declaraciones de valor normativo.

Una verdadera debilidad del concepto del SSE es que la perspectiva internacional esta ciertamente subrepresentadas en el trabajo de Daly (1992a). Él (Daly 1992a, p. 71) señala que el modelo («probablemente») debería estar diseñado para incluir los recursos importados. "Los mismos derechos de cuotas de recolección podrían exigirse para la importación de recursos y, por tanto,el mercado determinaría la proporción en que nuestro nivel de vida es sostenido por el agotamiento de los recursos nacionales o extranjeros. Los bienes finales importados serían ahora más baratos en relación con los bienes nacionales, en el supuesto que los extranjeros no limiten su recolección. Nuestros productos de exportación serían ahora más caros en relación a la producción nacional de mercancías de los países extranjeros. Nuestras posibilidades de comercio mejorarían, pero tendiríamos a una balanza de pagos deficitaria". Sin embargo, reconoce que la balanza de pagos puede cuidar de sí misma por medio de la libre fluctuación de los tipos de cambio. El equilibrio sería simplemente restaurado mediante un aumento en el precio de las monedas extranjeras en relación con el dólar. "Si los extranjeros están dispuestos a vendernos sus productos a cierto precio por debajo de los costes de producción, no debemos quejarnos." (Daly 1992, p. 71) Esta declaración revela la cosmovisión américo-céntrica de Daly y claramente excluye a los países pequeños de tratar de alcanzar una SSE. Además, incluso para una economía tan grande como los EE.UU., un repentino drástico cambio en la demanda de productos extranjeros, sin duda, causa trastornos importantes. Por lo tanto, sin la imposición de impuestos a la importación, la introducción del concepto de SSE de Daly (1992a) probablemente no sería factible. Implícitamente , por lo tanto, esta pidiendo el retorno a las barreras comerciales intensas, o incluso a la autarquía? Frente a esta cuestión a través de correspondencia por correo electrónico, el Sr. Daly respondió: "En cuanto a las relaciones internacionales no defiendo la autarquía, pero el comercio no puede ser libre, (...)" ( Daly 2002) Sin embargo no queda claro en su respuesta, cual sería la solución para su concepto de SSE.

Aparte del comercio internacional, también la inmigración podría causar problemas que no son abordado por Daly (1992a). Las presiones causadas por el aumento de la población a través de la inmigración podría entrar en conflicto con el régimen de certificados de nacimiento transferibles y, en general, con el intento de mantener la población constante. Por lo tanto, las fronteras deben estar cerradas a los inmigrantes. Por un lado, esto parece posición dura y tal vez poco ética. Por otra parte se podría argumentar que esto es mejor que explotar a los inmigrantes como mano de obra barata. Además, si esta política permitiera a un país convertirse en sostenible, se liberarían recursos para el desarrollo de los países más pobres. Es evidente que es preferible a permitir que los países más

concepto de suficiencia material; un sentimiento responsabilidad personal hacia todo lo creado y una extensión del hermanamiento con las generaciones futuras y otras formas de vida; humildad - no todo lo puede hacerse, debe hacerse y holismo p.ej. reconocer que el conjunto es mayor que la suma de sus partes. 
También existe un problema durante la transición hacia una economía en estado estacionario con respecto a los que ya son ricos y poderosos y a los dueños de los recursos. Daly sólo se refiere a estos últimos y señala que" (...) los actuales propietarios de recursos que sufrirían una pérdida de capital cuando se impongan límites de recolección de dichos recursos y, en equidad, deben ser compensados". Sin embargo, si esta compensación empujase estas personas por encima de los ingresos y la riqueza máximas, sería taxado de todos modos, por lo que sería equivalente a la expropiación, por lo menos parcial. Es ingenuo suponer que los ricos y poderosos también se inspiraran en la esperanza general del "crecimiento moral" y renunciarán a su posición y posesiones sin luchar. Aunque Daly sugiere que el nivel de ingresos máximo podría ser muy generoso en una primera fase, los que prevean que sus fortunas vayan a ser confiscadas vía impuestos, hará todo lo posible para evitar que esto ocurra. Por lo tanto, parece que una "revolución de tipo marxista" sería una condición necesaria para la SSE.

Booth (1998) considera que el crecimiento como una dinámica intrínseca del capitalismo. Con lo que comparte la visión Schumpeter que considera que la creación de nuevas industrias basadas en nuevas tecnologías es fundamental para el crecimiento macroeconómico. Estas nuevas industrias automáticamente crean nuevos problemas ambientales y, además, intereses creados que se oponen a las regulaciones ambientales o la imposición de las instituciones de Daly (1992a). Por lo tanto, sostiene que el capitalismo, al menos en su forma actual no puede ser sostenible y no es compatible con el paradigma de estado estacionario (Booth 1998).

\subsection{Crítica a la SSE: la segunda ley de la termodinámica}

La visión pre-analítica de Daly, que se ha descrito anteriormente, se basa en la interpretación de Georgescu-Roegen (1971) acerca de la ley de la entropía. En particular en lo que él denomina una "cuarta ley de la termodinámica", "el reciclaje completo es imposible (...) Los objetos materiales se deterioran de tal manera que las pequeñas partículas (moléculas) que pertenecían originariamente a estos objetos se disipan gradualmente más allá de la posibilidad de ser reintegrados de nuevo." (Georgescu-Roegen 1971, p. 60) Sin esta ley, y por lo tanto en Daly (1992a), la economía podría ser un sistema cerrado, porque un litro de gasolina, por ejemplo, podría ser quemado una y otra vez y nunca nada se agotaría. Aunque la cuarta ley de Georgescu parece plausible, es intuitiva y no se basa en argumentos, sino en una colección de ejemplos prácticos. No puede demostrar la imposibilidad teórica del reciclaje perfecto. De hecho, más bien de hecho lo contrario es cierto, y directamente contradice la primera ley22, que implica claramente la posibilidad del reciclaje completo (Hall, Cleveland et al. 1986; Ayres y Kneese 1989; Binswanger 1992; Söllner 1997; Ayres 1998).

Ayres (1998, p. 198) afirma que la "cuarta ley" de Georgescu-Roegen (1971) podría ser cierta sólo si" (...) los materiales recuperados y purificados, en principio, fueran insuficientes para mantener los bienes de equipo necesarios para la operación de recuperación". Él agrega, sin embargo, que esto no es cierto porque los materiales se encuentran atrapados en el campo gravitacional de la Tierra (Ayres, 1998). Incluso el $100 \%$ de reciclado es teóricamente factible si se dispone de suficiente

22 Conservación de la materia y la energía, 
ualquier elemento puede recuperarse de cualquier fuente Unlimited Pages and Expandeno difuso" (1998, p. 197). Así pues, el oro o el uranio, por ejemplo, en principio, podrían ser recuperados del agua del mar. Según Ayres (1998), el principal problema es la contaminación del medio ambiente hasta que todos los recursos no renovables estén agotados. Los peligros a largo plazo derivados de la actividad humana no se encuentran en la finitud de las reservas de recursos, si no en la fragilidad de los ciclos naturales autoorganizados. En su crítica a las interpretaciones erróneas de la ley de entropía, Ayres (1998) se refiere a algunos de los argumentos centrales de Daly ...:

"Los servicios provienen de dos fuentes, el stock de artefactos y el ecosistema natural. Los stocks de artefactos requieren throughput para su mantenimiento, lo que requiere recolección de recursos y la contaminación del ecosistema. En otras palabras, la estructura (baja entropía) de la economía se mantiene mediante la imposición de un coste de trastorno en el ecosistema. Desde la ley de la entropía sabemos que el aumento de entropía de los ecosistemas es mayor que la disminución de la entropía de la economía. Con el aumento del stock y el throughput usado en su mantenimiento, el creciente desorden exportados hacia el ecosistema en algún punto interferirá con su capacidad de prestar servicios naturales." (Daly 1992, p. 34)

La verdad central en este apartado, según Ayres simplemente no es verdad. El argumento de la cita anterior sólo sería cierto si "el ecosistema" se interpreta como el planeta tierra, separándolo del sistema solar, incluyendo el sol (Ayres, 1998). Ya que, sin embargo, se aplica a "los ecosistemas" como "la biosfera" mediante la insolación, la cita anterior es una interpretación errónea de la ley de la entropía. Ayres, a continuación, remarca un pasaje, cuando Daly (1992a, p. 277) afirma que en reconocimiento de un plazo de tiempo medio (una generación o una vida media) "(...) el crecimiento industrial se ve limitado por el stock de baja entropía terrestre, en lugar de por el stock de energía solar de baja entropía, que es superabundante pero irrelevante, porque la energía solar es el flujo limitado ..." Para Ayres (1998), Daly (1992a) tropieza en un punto, de hecho, en esta cita: Si bien la radiación solar es un flujo limitado, "(...) el flujo disponible de energía solar de baja entropía (exergía) es muy grande" (Ayres 1998, p. 197). La biosfera aparentemente sólo utiliza aproximadamente un $3 \%$ de la exergía solar que llegan a la superficie de la tierra (Ayres, 1998).

Ayres considera que muy pronto la tecnología será lo suficientemente avanzada para capturar el flujo de energía solar de manera más eficiente, por ejemplo: células fotovoltaicas y pilas de combustible de hidrógeno alimentada por energía solar. Por ejemplo, no afectaría el equilibrio térmico de la tierra si se cubrieran los desierto con dispositivos para capturar la energía solar y transformarla en hidrógeno. La superficie de la tierra tampoco es ningún límite, ya que, según Ayres (1998), los satélites pueden captar exergía solar y llega a la conclusión de que" (..) en el largo plazo, la exergía solar, sin duda, se encuentra disponible para uso humano en cantidades casi ilimitadas." Ayres (1998) posiblemente se refiere a la noción de una economía basada en el hidrógeno (por ejemplo: economía del hidrógeno), que posteriormente fue popularizada por Jeremy Rifkin (2002).

Aunque Ayres afirma que el consumo directo de la biomasa por los seres humanos requiere una pequeña fracción de esta cantidad, también menciona un estudio de Vitousek et al. (1986). En este

23 Energía disponible (Ayres 1998) 


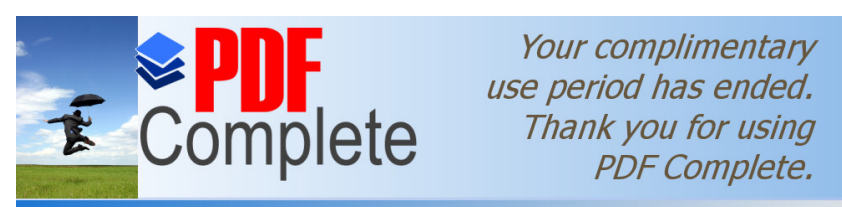

Click Here to upgrade to

Unlimited Pages and

de la producción de la biosfera ya es utilizada por los seres

los usos indirectos. En algún momento la población será demasiado grande, incluso si la energía se superabundante (a menos que los asentamientos en naves espaciales se consideren factibles). Ayres $(1998,199)$ y admite que incluso sostiene que "(...) una versión ligeramente enmascarada del dilema planteado por Malthus está sobre nosotros".

\section{Conclusión}

El objetivo de este trabajo es establecer un camino lógico desde el, ya ampliamente aceptado, paradigma de la sostenibilidad, tal como se definió por la Comisión Brundtland (WCED 1987) en una extensa crítica del paradigma del crecimiento económico, hacia la necesidad de la consecución de una economía que no crece - una economía en estado estacionario. Al final de este camino, se proporcionó y analizó críticamente un posible concepto para el logro de una economía como esta, el de Herman Daly. Se ha demostrado, que la mayoría de condiciones previas para el paradigma del crecimiento, encuentran sus raíces en la adopción de un concepto mecánico de valor. Generosas asunciones de los supuestos de sustituibilidad de los recursos, así como del capital natural e incluso del capital humano, junto con el optimismo aparentemente ilimitado en el progreso tecnológico, han sido identificados como las principales condiciones previas para la posibilidad teórica del crecimiento económico ilimitado.

Además, se ha demostrado que el crecimiento económico no es la panacea para la mayoría de los problemas de los la sociedad. Esto es cierto, en particular, si el crecimiento, medido en el PIB se convierte en poco rentables, lo que parece ser la lección de diversos estudios empíricos. Además según la cuarta ley de la termodinámica de Georgescu-Roegen (1971), el crecimiento ilimitado es físicamente imposible. Ayres (1998) por otro lado sugiere que el crecimiento ilimitado se convierte, en teoría, es posible, tan pronto como el flujo de energía solar se pueda utilizar más eficientemente con las futuras innovaciones tecnológicas. Aunque el razonamiento de Ayres (1998) parece correcto, sigue siendo cuestionable si la posibilidad teórica de reciclar el 100\% tiene alguna relevancia práctica. Además Ayres (1998) parece demasiado optimista sobre los avances en las tecnologías energéticas. El entusiasmo acerca de una próxima economía del hidrógeno, a la que parece hacer referencia, se está convirtiendo cada vez en más controvertida (por ejemplo: Luzzati y Franco 2005)

Daly (1992a) por otro lado exige un prudente escepticismo tecnológico. Antes que estas tecnologías estén disponibles, la humanidad estaría mejor servida intentando convertirse en estable. Los recursos naturales son considerablemente subestimados (El Serafy 1988; Daly 1992a) y los mecanismos del mercado no pueden ser invocados para proporcionar suficientes incentivo para los avances tecnológicos. El momento en que la economía del hidrógeno esté dispuesta a sustituir a la economía del carbón ${ }^{24}$ podría ser demasiado tarde - el daño en el ecosistema podría ser demasiado grande para recuperarlo25. Las cuotas de recolección de Daly (1992a), automáticamente encarecen los recursos naturales, al cargar una renta de escasez sobre los recursos. Esto no sólo orientará la investigación tecnológica hacia el desarrollo de dispositivos para captar mejor el flujo de energía solar, sino también permitir que la humanidad reduzca gradualmente el impacto de la contaminación.

$24 \mathrm{Y}$ no es cierto que esto llegue a suceder.

25 En un escala de tiempo humana. 
nás lejos y preguntarse si descubrir una fuente de energía ilimitada sería beneficioso para la humanidad actual, para la sociedad del crecimiento. Daly (1992a) considera que ese descubrimiento sólo aceleraría el proceso de destrucción del medio ambiente. Una explosión demográfica, junto con la rápida ampliación de la actividad económica podría causar el colapso de los ecosistemas y la aparición de las hambrunas y las guerras (Daly 1992).

Además, se ha mencionado ya que hay fuertes indicios de que la humanidad se aproxima a los límites de los ecosistemas, la mayoría de los cuales están directamente relacionados con el número total de personas en el planeta. Vitousek et al. (1986) señalan que alrededor del $40 \%$ del producto primario neto de la fotosíntesis terrestre (NPP) ya es apropiado por las actividades humanas. La Comisión Brundtland (WCED 1987) concluyó en 1987 que, a fin de garantizar los estándares de vida de EE.UU. para todo el mundo, esto requeriría una multiplicación de la producción económica en todo el mundo por un factor de entre cinco y diez (Vitousek, Ehrlich et al. 1986) - un objetivo, que es simplemente imposible ${ }^{26}$. El cambio climático, el agujero de la capa de ozono, la degradación de las tierras y la pérdida de diversidad biológica son una prueba más del impacto de la actividad económica y la proximidad de los límites ecológicos.

En una crítica socio-ética del crecimiento, ha quedado demostrado que el crecimiento económico ilimitado, aunque posible, puede ser indeseable. Indicadores alternativos al PIB muestran una disminución en el bienestar en los últimos 40 años. Por otra parte, la satisfacción del fin último (lo que puede ser) el cultivo de "las gracias de la vida" (Mill 1965 [1948]) parece estar en peligro por la necesidad por parte de la economía del crecimiento de un consumidor insatisfecho. Satisfacer deseos relativos insaciables se ha convertido en la razón de ser del sistema económico occidental. Al mismo tiempo en otras partes del mundo, la gente todavía se esfuerza por satisfacer sus necesidades más básicas.

Se ha argumentado que sin el crecimiento moral el concepto de SSE de Daly probablemente no sería factible. Sin embargo, la adopción de la meta del desarrollo sostenible, que se basa claramente en valores éticos y conceptos normativos, podría ser el primer signo de ese crecimiento. Sin embargo, los problemas de suficiencia, la frugalidad y, por encima de todo, cambios en el estilo de vida, siguen estando subrepresentadas en el discurso de la sostenibilidad. Lo mismo se aplica en primer lugar, para hacer frente a la superpoblación y, en segundo lugar para disminuir la desigualdad y liberar recursos en los países ricos. Eventualmente este discurso tiene que abordar estas cuestiones y, por tanto, no podrá ignorar el concepto de estado estacionario.

Quizás los economistas clásicos tuvieran razón, y el estado de equilibrio vendrá sobre la humanidad por sí misma. Quizás Keynes y Schumpeter tenía razón respecto el actual sistema económico sólo como un camino hacia un mejor (estable) orden económico. Mill (1988) y Daly (1992) sostuvieron que la transición voluntaria a lo que parece inevitable en cierto punto, podría evitar grandes

26 Los optimistas tecnológicos esgrimirán una vez más que estos límites podrán superarse por los avances de la bioquímica molecular (u otras disciplinas). Sin embargo, dados los considerables esfuerzos dedicados a producir cosechas con mayores rendimientos, el stock mundial de cereales ha ido disminuyendo considerablemente en los últimos años. (Brown 2004). 
Iro y crear las condiciones de vida para satisfacer a todos. un estado de equilibrio, incluso si la gente votase por él, podría ser compatible con el sistema capitalista actual. Así pues, no está claro si las instituciones propuestas por Daly (1992a) o Booth (1998) podrían poner el sistema capitalista dentro de los límites o si, como fue implícitamente asumido por Mill, Marx, Schumpeter y Keynes, una economía en estado de equilibrio sería igual al socialismo. Por otra parte, importa que sistema económico sea, si el crecimiento moral es tan fuerte como Daly espera?

\section{BIBLIOGRAFÍA}

AAGE, H. (1984). "Economic arguments on the sufficiency of natural resources."

ALLEN, R. L. (1994). Opening Doors. The Life and Work of Joseph Schumpeter. Europe. New Brunswick/London, Transaction Publishers.

AYRES, R. U. (1998). "Analysis: Eco-thermodynamics: economies and the second law." Ecological Economics

26(2): 189-209.

AYRES, R. U. and A. V. Kneese (1989). Externalities: economics and thermodynamics. Economy and Ecology:

Towards Sustainable Development. F. Archiburgi and P. Nijkamp. Boston, Kluwer: 89-118.

BARNETT, H. and C. Morse (1963). Scarcity and Growth. The Economics of Natural Resource Availability. Balitmore, John Hopkins Press.

BAUMGÄRTNER, S. (2003). "Entropy." Internet Encyclopedia of Ecological Economics Retrieved 12. February, 2006, from http://www.ecoeco.org/publica/encyc_entries/Entropy.pdf.

BINSWANGER, M. (1992). Information und Entropie. Frankfurt, Campus.

BLADEN, V. (1974). From Adam Smith to Maynard Keynes: the heritage of political economy. Toronto/Buffalo, University of Toronto Press.

BOOTH, D. (1998). The Environmental Consequences of Growth. London, Routledge.

BOULDING, K. E. (1964). The Meaning of the Twentieth Century. New York, Harper \& Row.

BOULDING, K. E. (1966). The economics of the coming spaceship earth. Valuing the Earth Economics, Ecology, Ethics. H. E. Daly and K. N. Townsend. Massachussetts, The MIT Press.

BOYDEN, S. (1992). Biohistory, The Interplay Between Human Society and the Biosphere. Paris, Casterton Hall, Park Ridge, UNESCO and Parthenon Publishing Group. 
the history of economic thought: the case of the stationary state."

BROWN, L. R. (2004). WORLD FOOD SECURITY DETERIORATING Food Crunch in 2005 Now Likely. London, Earth Policy Institute.

CANELLAS, S., A. Citalic González, et al. (in press). "Material Flow Accounting of Spain." International Journal of Global Environmental Issues Forthcoming.

CAVLOVIC, T., K. Baker, et al. (2000). "A meta-analysis of environmental Kuznets studies." Agriculture and Resource Economics Review.

CLAEYS, G. (1987). Der soziale Liberalismus John Stuart Mills: eine Einführung. Der soziale Liberalismus John Stuart Mills. Ders. Baden-Baden, Nomos: 9-31.

COSTANZA, R., R. d'Arge, et al. (1997). "The value of the world's ecosystem services and natural capital." Nature 387: 253-260.

COSTANZA, R., R. B. Norgaard, et al. (1997). An Introduction to Ecological Economics. Florida, CRC Press LLC.

DALY, H. E. (1981). Postscript: unresolved problems and issues for further research. Energy, Economics, and the Environment. H. E. Daly and A. F. Umana. Boulder, Westview Press: 165-185.

DALY, H. E. (1991). Elements of environmental macroeconomics. Ecological Economics: The Science and Management of Sustainablitiy. R. Costanza. New York, Columbia University Press: 3246.

DALY, H. E. (1992a). Steady-state economics. London, Earthscan Publications Ltd.

DALY, H. E. (1992b). "Allocation, distribution, and scale: towards an economics that is efficient just, and sustainable." Ecological Economics 6: 185-193.

DALY, H. E. (1996). Beyond Growth. The Economics of Sustainable Development. Boston, Beacon Press: The economy as an isolated system.

DALY, H. E. (2001). Unwirtschafliches Wachstum und Globalisierung in einer vollen Welt. Natur und Kultur, Transdisziplinäre Zeitschrift für ökologische Nachhaltigkeit. 2.

DALY, H. E. (2002). SSE \& foreign trade. C. Kerschner: e-mail correspondence.

DALY, H. E. and J. B. Cobb (1989). For the common good. Boston, Beacon Press. 
Some Common Misunderstandings and Further Issues Concerning a Steady- State Economy. Valuing the Earth - Economics, Ecology, Ethics. H. E. Daly and K. N. Townsend. Massachussetts, The MIT Press: 366.

EDMONDS, J. A. and J. Reilly (1985). "Time and uncertainty: analytical paradigms and policy requirements."

EHRLICH, P. R. and J. P. Holdren (1971). "Impact of population growth."

EL SERAFY, S. (1988). The proper calcualtion of income from depletable natural resources. Washington, DC, World Bank.

EL SERAFY, S. (1997). "Green accounting and economic policy." Ecological Economics 21(3): 217229(13).

EUROSTAT (2001). Economy-wide material flow accounts and derived indicators. A methodological guide. Luxembourg, Office for official Publications of the European Communities.

EUROSTAT (2002). Material use in the European Union 1980-2000: Indicators and analysis. Luxembourg, Eurostat, Office for Official Publications of the European Communities.

FISCHER, I. (1906). The Nature of Capital and Income. London, Macmillan.

GEORGESCU-Roegen, N. (1971). The Entropy Law and the Economic Process. Cambridge. Mass., Harvard

University Press.

GEORGESCU-Roegen, N. (1976). Energy and economic myths: institutional and analytical economic essays. New York, Pergamon Press.

GEORGESCU-Roegen, N. (1977). "The Steady State and Ecological Salvation: A Thermodynamic Analysis."

BioScience 27(4): 266-270.

GILBERT, G. (1993). Introduction to 1993 edition of. Malthus, Thomas R (1993 [1798]). An Essay on the Principle of Population. Oxford/New York, Oxford University Press.

GILJUM, S. (2004). "Trade, material flows and economic development in the South: The example of Chile." Journal of Industrial Ecology 8 (1-2).

GOODLAND, R. (1991). Tropical deforestation: Solutions, ethics and religion. Environment Department Working Paper 43. Washington, DC, The World Bank. 
2). Population, technology, and lifestyle. T. f. g. e. r. t. t. e. Washington, DC, Island Press.

HABERL, H., K.-H. Erb, et al. (2001). "Changes in Ecosystem Processes Induced by Land Use: Human Appropriation of Net Primary Production and Its Influence on Standing Crop." Global Biogeochemical Cycles

15: 929-942.

HABERL, H., M. Fischer-Kowalski, et al. (2004). "Progress towards sustainability? What the conceptual framework of material and energy flow accounting (MEFA) can offer." Land Use Policy 21: 199-213. 